\title{
Las fake news durante el Estado de Alarma por COVID-19. Análisis desde el punto de vista político en la prensa española.
}

\section{The fake news during the COVID-19 State of Alarm. Analysis from the political point of view in the Spanish press.}

Aránzazu Román-San-Miguel ${ }^{1}$. Universidad de Sevilla. España

arantxa@us.es

$\overline{[C V]}$ G

Nuria Sánchez-Gey-Valenzuela. Universidad de Sevilla. España.

nuriasanchezgey@gmail.com

$[\mathrm{CV}]$ (1) $\mathrm{C}$

Rodrigo Elías-Zambrano. Universidad de Sevilla. España.

rodrigoelias@us.es

$[\mathrm{CV}] \odot \mathrm{R}^{\mathrm{D}} \mathrm{O}$

Cómo citar este artículo / Referencia normalizada

Román-San-Miguel, A., Sánchez-Gey Valenzuela, N. y Elías-Zambrano, R. (2020). Las fake news durante el Estado de Alarma por COVID-19. Análisis desde el punto de vista político en la prensa española. Revista Latina de Comunicación Social, 78, 359-391. https://www.doi.org/10.4185/RLCS-2020-1481

\section{RESUMEN}

Introducción: Desde que en diciembre de 2019 se empezara a hablar en España sobre el coronavirus que estaba afectando a China, los rumores y las noticias imprecisas poblaron el mundo. Cuando la enfermedad llegó a Europa, la proliferación de información se multiplicó. Desde que se decretara el Estado de Alarma, los bulos y las fake news han sido una constante, que se ha reflejado en las informaciones de los medios de comunicación. Metodología: En este trabajo se analizan las informaciones publicadas en la prensa española sobre fake news relacionadas con la política, las polémicas declaraciones del jefe del Estado Mayor de la Guardia Civil y las redes sociales; para conocer el volumen de noticias y el tratamiento que los medios han hecho de ellas. Se ha usado una metodología mixta, cualitativa/cuantitativa con el apoyo de la herramienta MAXQDA 2020. Resultados: Tras el análisis de 229 textos se puede afirmar que el tema del que se han publicado más informaciones relacionadas con fake news es política (48,47\%), seguido de las redes sociales $(28,8 \%)$ y las polémicas declaraciones del jefe del Estado Mayor de la Guardia Civil (22,7\%); aunque en todo momento el debate político ha estado presente en las informaciones. Discusión: Este trabajo abre una línea de investigación sobre si se puede limitar la propagación de informaciones perjudiciales en una pandemia o si está por encima la libertad de expresión. Conclusiones: Los medios que se sitúan en la

${ }^{1}$ Autora de correspondencia 
derecha ideológica, han publicado más informaciones con mayor contenido político $(73,87 \%)$, frente a los medios de izquierda con solo un $26,13 \%$.

PALABRAS CLAVE: Bulo; COVID-19; medios de comunicación; noticias falsas; redes sociales; política; credibilidad.

\begin{abstract}
Introduction: Since December 2019, when talk began in Spain about the coronavirus that was affecting China, rumors and vague news populated the world. When the disease reached Europe, the proliferation of information multiplied. Since the State of Alert was decreed, hoaxes and fake news have been a constant, which has been reflected in media reports. Methodology: This paper analyses the information published in the Spanish press about fake news related to politics, the controversial declarations of the Chief of Staff of the Guardia Civil and social networks; to know the volume of news and the treatment that the media has given to them. A mixed, qualitative/quantitative methodology has been used with the support of the MAXQDA 2020 tool. Results: After the analysis of 229 texts, it can be stated that the topic of which most information has been published about politics (48.47\%), followed by social networks (28.8\%) and the controversial statements of the Chief of Staff of the Guardia Civil (22.7\%); although at all times the political debate has been present in the information. Discussion: This work opens a line of investigation on whether the spread of harmful information can be limited in a pandemic or whether freedom of expression is above it. Conclusions: The media on the ideological right have published more information with greater political content $(73.87 \%)$, compared to the left-wing media with only $26.13 \%$.
\end{abstract}

KEYWORDS: Bulo; COVID-19; mass media; fake news; social media; politics; credibility.

\title{
CONTENIDO
}

1. Introducción. 2. Revisión Bibliográfica. 3. Objetivos y Metodología. 4. Resultados. 5. Conclusiones y Discusión. 6. Bibliografía. 7. Curriculum Vitae

\section{Introducción}

El término fake news se ha convertido en omnipresente con bastante rapidez. No obstante, en la actualidad, siguen existiendo medios que difunden más noticias falsas - relativamente oscuras- en comparación con el proceder de los medios de comunicación considerados solventes y tradicionales. (Nelson y Taneja, 2018). Es más, aunque las fake news, ciertamente, no son un fenómeno nuevo (Parra y Oliveira, 2018, Blanco-Herrero y Arcila-Calderón, 2019), en determinados medios sí se ha acentuado su publicación durante la pandemia de COVID-19 que se está produciendo en el mundo. El término 'información', partiendo del concepto periodístico, tiene que contener en sí mismo la verdad, sin necesidad de más adjetivaciones (Brajnovic, 1979). Pero en la actualidad la información no llega solamente desde los medios de comunicación tradicionales, que es la que está regulada en España por el Tribunal Constitucional, como derecho fundamental que es, sino que puede llegar desde cualquier lugar y filtrarse en el saber colectivo como verdad, sin serlo (Campos, 2008).

La falta de verdad, o veracidad como algunos prefieren referirse a ella, se escuda en la libertad de expresión (Tandoc et al., 2018), y cuando se intenta acabar con esta distorsión de la realidad, se puede caer en la censura. Como sostiene Azurmendi (2005:40) "la información no es exclusiva" del sector periodístico "ni la única información con difusión social es la periodística". 
Resulta complejo conjugar el derecho a la información, con el derecho a informar y a tener libertad de expresión en todos los medios a través de los que puede llegar la información a la ciudadanía. De este ámbito se ocupan diversos trabajos desde la jurisprudencia (Piñas, Villacrés y Patricio, 2019 y Escandón, 2019). También existen estudios que analizan cómo pueden protegerse los derechos fundamentales en las redes sociales abordando, por ejemplo, el derecho a rectificación en el ámbito español y latinoamericano (Ortega-Ruiz y Forero, 2018). Este trabajo no va a entrar en términos jurídicos, pero sí es consciente de que el objeto de estudio puede actuar en este contexto.

La repercusión de las fake news sobre el coronavirus viene siendo de tal importancia que la plataforma Salud sin Bulos, creada por la Asociación de Investigadores en Salud en España (AIES), ha implementado en su página web una pestaña para abordar los engaños acerca del coronavirus. Pero, más allá de ciertas plataformas que intentan desmentir noticias falsas, en la actualidad estas han cobrado una relevancia tan importante que el Gobierno ha tomado medidas para frenarlas. Así, en un supuesto lapsus, el jefe del Estado Mayor de la Guardia Civil, José Manuel Santiago, en una de las numerosas comparecencias de cargos de las fuerzas y cuerpos de seguridad del Estado, llegó a afirmar que la Guardia Civil trabajaba "para minimizar las críticas a la gestión del Gobierno" en el contexto de la lucha contra las fake news "susceptible de generación de estrés social y desafección a instituciones del Gobierno" (Cadena SER, 2020). Estas palabras, pronunciadas el 19 de abril de 2020 fueron interpretadas como una injerencia de las fuerzas de seguridad en la libertad de expresión. Al día siguiente, el 21 de abril de 2020, el jefe del Estado Mayor de la Guardia Civil matizaba sus palabras: "Cuando hablo de bulos y desinformación, me refiero a que la Guardia Civil trata de analizar actividades de origen incierto"; a lo que añadía que todas las actividades de la Guardia Civil se realizan "respetando el principio a la libertad de expresión" (El Mundo, 2020). Todas estas declaraciones se emitieron en directo por las principales cadenas de televisión de España y de ellas se hicieron eco todos los medios de comunicación, tanto radiofónicos como digitales e impresos del país; sin distinción de ideologías.

En este contexto, resulta de especial interés analizar las informaciones sobre noticias falsas que han aparecido en los medios de comunicación escritos tradicionales, ya sea en su edición impresa o digital; pues, en este momento, la proliferación de informaciones sobre el fenómeno de las fake news, se ha hecho manifiesto en los medios. Y es que este término ha entrado, de pleno, a formar parte de la agenda mediática. No porque estén apareciendo noticias falsas en demasía en los medios de comunicación -que sería atentar contra el principio de veracidad que debe estar presente en la práctica periodística- sino porque, en un momento en que la ciudadanía y los agentes sociales de todo tipo pueden difundir libremente información a través de las redes sociales, el falseamiento de la realidad se está dando a niveles muy elevados (Silverio, 2018 y Shu et al., 2017).

\subsection{Maldita.es vs. Newtral}

La periodista Ana Pastor, imagen de la cadena de televisión La Sexta, fundó en 2018 Newtral, una compañía de contenido visual que, entre otras áreas de negocio, está orientada a la verificación de noticias y la innovación en el periodismo a través del factchecking de hechos. No era la primera vez que se dedicaba a esta función, ya que desde 2013, en su programa 'El Objetivo' de la misma cadena, realizaba esta función de verificación, primero con 'Maldita Hemeroteca', a través de Maldita.es. Después crearía Newtral, que fue el primer medio español en entrar en la International FactChecking Network, organismo internacional de verificadores independientes. Y es que, "tras 5 años verificando informaciones, Newtral se ha incorporado en marzo de 2019 al programa de verificación de datos externos de Facebook" (Alonso, 2019, p. 46). 
La Sexta, junto con Antena 3, forman el segundo grupo de comunicación más grande en España, Atresmedia, solo por detrás de Mediaset. Asimismo, La Sexta nació en 2006 al concederle el Gobierno de Rodríguez Zapatero una licencia de TDT a un grupo formado, entre otros, por Televisa, Globomedia (Emilio Aragón) e Imagina Media, con Roures (Mediapro) como figura más visible. Imagina tiene una pequeña participación en Atresmedia y de aquel dependen programas como 'El Intermedio', 'El Objetivo de Ana Pastor', 'La Sexta Noticias' o 'Al Rojo Vivo'. Cabe recordar las palabras de José Manuel Lara Bosch (hijo del fundador de Planeta y presidente desde 2003 hasta 2015): "con La Sexta quiero hacer una televisión de centroizquierda" (Reig y Labio, 2017, p.126).

Por otra parte, está la plataforma Maldita.es, que se autodefine en su página web como un medio sin ánimo de lucro cuyo fin es dotar a los ciudadanos de "herramientas para que no te la cuelen", centrados en el control de la desinformación y el discurso público mediante técnicas de verificación de hechos (fact cheking) (Maldita.es, 2020).

Desde junio de 2018, Maldita.es también forma parte de Fact Checking Network y, según su página web, son el único medio español que formó parte del Grupo de Alto Nivel sobre fake news y desinformación nombrado por la Comisión Europea en 2018. Pero no se puede olvidar que Maldita.es y Maldito bulo parten de Maldita Hemeroteca que es un proyecto creado por dos periodistas, Clara Jiménez Cruz y Julio Montes, y que ambos han trabajado en La Sexta; es más Maldito Bulo tenía una sección en 'El Objetivo' de La Sexta y colaboraba con otros programas de la cadena ('Al Rojo Vivo', 'Más Vale Tarde', 'La Sexta Noche'). Ahora ya no mantienen esa relación, pero sí sus colaboraciones con 'Julia en la Onda' de Onda Cero. Asimismo, en ocasiones han trabajado con eldiario.es (Magallón-Rosa, 2018).

Como se puede observar la pugna entre Maldita.es y Newtral es clara, ambos dicen ser los primeros en formar parte del mismo organismo internacional de verificación, por ejemplo, pero esta tensión entre plataformas es solo por la posición en el mercado, ya que tanto la línea ideológica de Newtral como de la de Maldita.es es de izquierdas. La pugna de ambas plataformas no es objeto de este trabajo, pero sí han quedado reflejados en este trabajo las reticencias o el apoyo de los diferentes medios a ellas dependiendo de su posición ideológica.

\section{Revisión Bibliográfica}

Parra y Oliveira (2018) realizaron una revisión de la literatura que existe sobre fake news situando el surgimiento de las mismas en el siglo XIX. Un momento en el que empezaron a proliferar los periódicos debido al avance de las nuevas tecnologías. Así, si los trenes y el barco de vapor fueron los medios de transporte que propiciaron la primera noticia falsa de la historia en 1835, publicada por The Sun (Salas, 2019); en el siglo XXI Internet se postula como el medio de transporte más ágil y veloz, además de propagador de información. Hasta ahora, dentro de Internet, las redes sociales han sido las propagadoras más activas de las denominadas fake news, considerándose a los medios de comunicación como los portadores de la verdad, más allá de los bulos (Tandoc et al., 2018). De este modo Blanco-Herrero y Arcila-Calderón sostienen que la comunicación online y, en concreto, las redes sociales, son las culpables de la aparición de las noticias falsas (Blanco-Herrero y ArcilaCalderón, 2019).

Desde 2018 existen varios estudios donde se testa la preocupación de los internautas españoles ante las fake news, como el realizado por Digital News Report que cifra esta inquietud en el 69\% de los usuarios de Internet (Vara, 2018). En la edición de 2019 este informe mide la intranquilidad de la población por este tipo de noticias y dice que "la mayoría de los internautas españoles (68\%) está 
preocupado por discernir lo que es verdadero o falso en Internet, si bien esta zozobra afecta especialmente a los mayores de 45 años (70\%), frente los menores de 25 años (57\%)" (Vara, 2019: párr. 7). Por tanto, parece claro que los españoles están interesados por saber si las informaciones que reciben, a través de las redes sociales, pero también desde los medios de comunicación, son verdaderas o falsas. De hecho, existe un grado de desconfianza en lo que publican los medios de comunicación. Así, quienes "eligen los medios digitales se muestran mucho más desconfiados (sólo un 39\% se fía) que los que prefieren los medios tradicionales como la TV (51\%) y la radio (47\%)" (Vara, 2019: párr. 4). Aunque la televisión y la radio ya están también en Internet, con una programación igual o similar a la emitida a través de los medios convencionales (Vara, 2019). En este sentido los profesionales de la información tienen una gran responsabilidad para acabar con la desconfianza de la ciudadanía ante la información falsa (Román-San-Miguel, 2019, López-Borrull, Vives-Gràcia y Badell, 2018).

La población, a la vez que se preocupa cada vez más por cuidar su salud física y mental (Bakir y McStay, 2018), también debe cuidar su salud informativa; pues como asegura Amorós "leer y creer fake news se carga nuestra salud informativa" (2018, p. 14). Tanta importancia llegan a tener las noticias falsas en la salud de la población, que la Organización Mundial de la Salud (OMS) tuvo que emitir un comunicado, en febrero de 2020, donde advertía de una nueva enfermedad que denomina 'informademia' o 'infodemia', según las traducciones. En este informe la OMS advertía que:

El brote del 2019-nCoV y su respuesta vienen acompañados de una enorme 'informademia', una sobreabundancia de información a veces precisa y a veces no que hace difícil que la gente halle fuentes fiables y seguras cuando las necesitan (...) La Organización está trabajando 24 horas al día para identificar los rumores más difundidos que puedan perjudicar la salud de la población, como medidas de prevención falsas o curas. Estos mitos se refutan entonces con información demostrada (Europa Press, 2020).

De este comunicado se hicieron eco todos los medios de comunicación y las agencias de noticias en España.

La población consume noticias falsas como verdaderas con demasiada frecuencia (McGonagle, 2017), puesto que recibe la información que le llega a través de las redes sociales igual que la que encuentra en medios de comunicación tradicionales. Esto es lo que concluye un estudio realizado por investigadores de diferentes universidades italianas. En este trabajo se analizan cinco redes sociales y la información que dan sobre COVID-19, en concreto evalúa el compromiso e interés de los usuarios sobre el COVID-19 y la evolución del discurso tanto de información veraz como cuestionable. En este sentido dicho trabajo concluye con que no existen diferencias significativas en sus patrones de difusión entre las informaciones marcadas como confiables y las cuestionables (Cinelli et al., 2020).

Esto quiere decir que la información veraz y la que no lo es, se difunde a través de las redes sociales con la misma fluidez y siguiendo los mismos patrones, de forma que resulta difícil separar información veraz de fake news (Flintham et al., 2018). Las noticias falsas además aprovechan los productos novedosos de "gigantes tecnológicos como Google, Facebook y Twitter", que son las plataformas en las que se difunde la mayor parte de las informaciones falsas, generando un flujo de información casi imposible de controlar (Richter, 2018). Además, llegan a tener gran relevancia por la gran difusión que le proporcionan los medios digitales y, como se ha apuntado, las redes sociales (Allcott y Gentzkow, 2017; Blanco-Herrero y Arcila-Calderón, 2019).

En general, la ciudadanía busca información y le hace un seguimiento exhaustivo cuando se producen situaciones de crisis y, en consecuencia, el consumo de información se incrementa 
exponencialmente. Incluso en un contexto de medios de comunicación en el que el consumo de noticias ha aumentado mucho de manera ocasional y con la mediación de plataformas de medios sociales (Fletcher y Nielsen, 2018), las personas con mayor disponibilidad seguirán probablemente expuestas a noticias de una mayor variedad de fuentes, mientras que las personas con menor disponibilidad seguirán probablemente consumiendo noticias de las fuentes más populares (Nelson y Taneja, 2018). De hecho, en Estados Unidos, en el caso del Covid-19, "el 92\% de los adultos (...) accedieron frecuentemente a las noticias sobre la pandemia, registrando un aumento de $34 \%$ sobre el período previo a la emergencia sanitaria" (Casero-Ripollés 2020). En el caso español ya tenemos algunos datos; así, desde el decreto del Estado de Alarma del 14 de marzo y hasta el 10 de abril se publicaron 184.057 noticias sobre 2019-nCoV y COVID-19, lo que supone un 63,74\% del total que fueron 288.781 informaciones recuperadas con la ayuda de la base de datos My news. En este sentido en un mes desde el decreto del Estado de Alarma, se publicaron casi el doble de noticias que en los dos meses anteriores a dicho decreto (Lázaro y Herrera, 2020).

Es más, tras analizar las declaraciones hechas por el gobierno de España a través de Twitter durante el estado de alarma, se puede concluir que dentro de las publicaciones con mayor éxito encontramos un tweet de contenido netamente publicitario, publicado el 15 de marzo, en el que aparece el cartel de la campaña "Este virus lo paramos unidos", pero lo más importante con una llamada a no compartir fake news (Castillo-Esparcia, Fernández-Souto y Puentes-Rivera, 2020).

La ciudadanía no puede llegar a la verdad absoluta, más allá de verificar algunos hechos, al igual que no puede crear grandes mentiras, porque, entre otras cosas, no tiene capacidad de difusión (Rapp y Salovich, 2018). Solo grandes grupos de presión, estructurados y organizados, pueden crear grandes mentiras que se difundan como verdad. Asimismo, si estos grupos organizados crean una realidad, que puede ser incierta, la población la aceptará como real. La capacidad de cualquiera de crear una fake news o un bulo es muy limitada, y solo quienes tienen poder pueden expandirla e incluso implantarla como verdad. Por este motivo, Carrera (2018) sostiene que no se puede refutar la mentira con hechos, sino que es necesario sostener y aportar argumentos y documentos, y que cuando intentan convencernos de que vivimos en la era de la posverdad, por el hecho de no tener capacidad para poder controlar las falsedades que se difunden a gran velocidad a través de las redes sociales, es una falacia puesto que nunca esta capacidad ha existido.

No obstante, en la actualidad la ciudadanía ya no se conforma con lo que escucha y lee, sino que es crítica con la información que recibe. Según un estudio realizado por investigadores de Digilab (Masip et al., 2020:3), en España, "la crisis del coronavirus ha provocado que el 78\% de los ciudadanos se informe más que antes de la pandemia, y el 52\% lo hace tres o más veces al día cuando antes de la crisis sólo lo hacía el 28\%". Resulta llamativo que, según este estudio, el 77,4\% de los encuestados opina que "los medios están condicionados o muy condicionados por su línea editorial en el tratamiento informativo de la pandemia"; además "el 44,6\% indica que los medios están tratando esta información de forma sensacionalista y generando una alarma social innecesaria".

Del mismo modo, resulta importante señalar que, según el estudio de Digilab, durante la pandemia, "aunque el $80,3 \%$ dice haber recibido noticias falsas o de dudosa veracidad, estas proceden mayoritariamente de las redes sociales y aplicaciones de mensajería instantánea $(64,3 \%)$. Y WhatsApp es la principal puerta de entrada de las noticias falsas". Y lo que resulta más novedoso es que "el 73,5\% de las personas encuestadas dice comprobar las noticias falsas, aunque sea sólo de las noticias que le interesan". Lo cual ya indica un cambio de actitud en la población, que no se cree todo lo que consume, sino que intenta contrastar la información; y este contraste de información lo hace, en primer lugar, a través del buscador Google y, en segundo, a través de los medios de comunicación. Contrariamente a lo que se podría pensar, con plataformas como Maldita.es o 
Newtral, entre otras muchas (Vázquez-Herrero, Vizoso y López-García, 2019), que tan de moda se han puesto en los últimos años, la comprobación a través de fact checkers solo la hace el 10\% de los encuestados. Además, normalmente la rectificación llega tarde, cuando ya se ha difundido la información y se ha dañado la imagen de quien se ve afectado (Kim, Moravec y Dennis, 2017).

Por tanto, si la ciudadanía utiliza los medios de comunicación tradicionales para contrastar la falsedad y, como afirma Carrera (2018), estos están dentro del círculo de la posverdad; ¿dónde habita la verdad? Una vez más las personas acuden a otros emplazamientos para informarse, más allá de los medios: informes, trabajos de investigación, libros, etc. (Corner, 2017). En definitiva, la ciencia sigue siendo el método necesario en democracia (Del-Fresno-García, 2019). Un argumento que también está presente en otros trabajos de investigación (Andreu-Sánchez y Martín-Pascual, 2020 y The lancet, 2020). Por supuesto, todo mediatizado bajo el paraguas de Internet, controlado por un puñado de multinacionales, mayoritariamente cinco: Microsoft, Apple, Amazon, Facebook y Google (Zuazo, 2018).

\section{Objetivos y Metodología}

Este trabajo de investigación parte de tres hipótesis:

1. Diferentes actores sociales han utilizado las redes sociales para difundir bulos a favor y en contra de la gestión de la crisis por parte del Gobierno, y estos han llegado a los medios de comunicación.

2. Los partidos políticos se han acusado mutuamente de difundir bulos y noticias falsas durante el Estado de Alarma, y las informaciones falsas se han colado en las agendas de los medios tradicionales.

3. El Gobierno, en su estrategia de comunicación, ha querido acabar con los bulos, pero esta decisión se ha vuelto en su contra al saberse que la unidad de ciberdelincuencia de la Guardia Civil estaba trabajando contra estas informaciones falsas, puesto que los medios de comunicación han utilizado ideológicamente esta supuesta censura del Estado. Asimismo, hay que tener en cuenta que la opción que se está presentando para los ciudadanos contra estos bulos es acceder a diversas plataformas que trabajan para combatirlos, como Maldita.es o Newtral, pero estas tienen una línea ideológica determinada que puede poner en duda su función. (Bernal-Triviño y Clares-Gavilán, 2019).

A partir de estas hipótesis surgen una serie de preguntas que se identifican con los objetivos de este trabajo:

O1. Averiguar cuál ha sido el volumen y el tratamiento que los medios han hecho sobre las fake news durante la pandemia, en relación a temas políticos, redes sociales y sobre las declaraciones del jefe del Estado Mayor de la Guardia Civil.

O2. Saber si los medios de comunicación se han hecho eco de diferentes bulos o noticias falsas que han circulado por las redes durante la pandemia y si lo han hecho con sesgo ideológico.

Para dar respuesta a los objetivos planteados, se han seleccionado dos medios de ideología de izquierda o centro-izquierda: El País y El Periódico; y otros dos de ideología de derechas o centroderecha: El Mundo y $A B C$. Esta distinción se recoge del buscador prensadigital.com que fue el primer buscador de periódicos y diarios en España. Además de las aportaciones de autores como Cachán (1995), Gómez (2010), Reig (2011) o Nogales y Mancinas (2014). Se han analizado las informaciones sobre fake news y bulos aparecidas en las ediciones digitales (aunque las que estaban bajo suscripción se han consultado en papel) de estos medios durante el Estado de Alarma decretado por el Gobierno. El período estudiado abarca desde el 16 de marzo hasta el 9 de mayo, cuando acaba la tercera prolongación del Estado de Alarma en España. 
Se han seleccionado medios de comunicación escritos por ser los medios que, según el EGM de abril de 2020 han aumentado su audiencia. Un estudio que además asegura que "los medios siguen valorándose positivamente por más del $90 \%$ de los encuestados, aunque empieza a percibirse cierta saturación de información sobre la crisis sanitaria" (EGM, 2020, párr. 1). La selección de medios se ha hecho teniendo como referencia el EGM I Ola de 2020 y atendiendo a medios que sean de carácter general y ámbito nacional, donde aparece El País en primer lugar, seguido de El Mundo, $A B C$ y El Periódico.

En este trabajo se utiliza una metodología mixta, mezclando el enfoque cualitativo y cuantitativo (Johnson et al., 2007), ayudándonos de la herramienta de análisis MAXQDA Analytics Pro 2020 (Release 20.0.8). De un lado, y mediante la metodología cuantitativa, este trabajo hace un recuento de las informaciones aparecidas relacionadas con el objeto de estudio, así como el espacio dedicado a las mismas; de otro lado, y para el análisis cualitativo, para identificar la objetividad/subjetividad de la información, se atiende a los diferentes términos que se usan en las informaciones y cómo se relacionan entre ellos, una identificación en la que ayudará MAXQDA2020. Este programa permite exportar nubes y combinaciones de palabras en .jpg, así como datos en formato Excel. En este trabajo se combinan ambos formatos. El método de investigación mixto enriquece la muestra, se le da una mayor fiabilidad con el uso de la herramienta adecuada, en este caso un programa informático, se aporta integridad al tratamiento de la muestra y se optimizan los significados dando mayor perspectiva a los datos (Collins et al., 2006).

Para seleccionar las informaciones se han establecido unos ítems que son los que han determinado si el contenido en cuestión es añadido (o no) por su relación directa con la temática abordada. Estos ítems son los términos que más se repiten en relación con las fake news o informaciones falseadas. Así, las palabras elegidas para hacer el cribado de documentos son: fake news; datos, noticia o información falsa; bulo; desinformación; mentira; rumores; noticias o informaciones fiables; veracidad; verdad. También se han incluido los términos resultantes de estas raíces. Con ello, los singulares y plurales, los verbos, adjetivos y nombres de la misma raíz, así como los contenidos considerados sinónimos.

\subsection{Diseño de la Investigación}

Una vez realizado el vaciado de los distintos periódicos seleccionados se ha establecido una clasificación por temas. Aunque la temática central es la información falsa y el COVID-19 dentro de esta se han analizado en profundidad las informaciones falsas relacionadas con la polémica creada por las declaraciones del jefe del Estado Mayor de la Guardia Civil, el general José Manuel Santiago, en las que citó como línea de trabajo sobre los bulos "minimizar ese clima contrario a la gestión de crisis por parte del Gobierno" (Ortega, 2020 tuits 3 y 4). Estas formarían una parcela del estudio. Las declaraciones de diferentes altos mandos de las Fuerzas y Cuerpos de Seguridad del Estado durante las primeras semanas del Estado de Alarma han formado parte del discurso comunicativo del Gobierno (López-García, 2020).

En el siguiente apartado de la clasificación se incluyen noticias cuya temática está relacionada con bulos en política. Con este término se señalan las noticias en las que se hace referencia a un político o partido o institución con implicación en una información falsa, qué ha dicho o de qué se le acusa de haber dicho sobre una información falseada o difundido un bulo.

En cualquier caso, y sin dejar de condenar la difusión de estas noticias desde la moral y ética ciudadana, habrá que esperar aún para ver el desarrollo de esta situación, pues, aunque el 
propio Gobierno ha asegurado estar trabajando en ello, la difusión de fake news o bulos no está contemplada como delito en el Código Penal de nuestro país (Espinosa, 2020, p.57).

El tercer peldaño de la clasificación está formado por las noticias sobre iniciativas para evitar la difusión de fake news a través de aplicaciones móviles o redes sociales. Las redes sociales se han convertido en las mayores difusoras de bulos.

Las nuevas tecnologías de la información han favorecido la democratización informativa, sin embargo, este proceso comunicativo bidireccional por el cual los ciudadanos se pueden convertir en el origen de las noticias se encuentra exento de controles de veracidad, por lo que desaparece el rigor informativo y la verificación de datos, cualidades intrínsecas del Periodismo (Alonso, 2019, p. 32).

En este punto se hallan las noticias relacionadas con la vigilancia de las redes sociales para la difusión de bulos y a su vez la polémica por la vinculación de este control con la libertad de expresión recogida en la Constitución Española.

Los medios de comunicación, dentro de su función social de desmentir informaciones falsas, publicándolas quizá puedan estar contribuyendo precisamente a lo contrario. Polage (2012) asegura que nuestra mente termina dando por cierta la información que no recordamos con exactitud pero que nos suena de algo. "Y ni siquiera sirve de algo desenmascarar la noticia falsa, porque al desmentirla inevitablemente la repetimos, y eso facilita su almacenamiento en el cerebro" (Amorós, 2018, p. 100). Por tanto, si no se recurre a esa función social de los medios la motivación pasaría a ser de otra índole. Por ejemplo, el hecho de que las noticias falseadas sean más atractivas y se compartan más, puede traducirse en beneficios económicos para los medios de comunicación, contándolas o desmintiéndolas, y por ello estos bulos se cuelan en la agenda de los medios. Como recoge la red de ética y periodismo de la Fundación Nuevo Periodismo Iberoamericano, las "estrategias de viralización como el click-bating son prácticas habituales en muchos medios de comunicación, que no se corresponden con la visión del periodismo como servicio público y social" (Lotero-Echeverri, Romero-Rodríguez y Pérez-Rodríguez, 2018, p. 298). Además, según se recoge en la Constitución, el periodista tiene la obligación de emitir información veraz, así que si informa de un hecho, a sabiendas de que es falso, está incumpliendo con ese imperativo legal. No obstante, no siempre esta dejadez de funciones se denuncia ante los tribunales sino que "el único castigo es el hecho de que el telespectador deje de creer en determinado medio de comunicación o profesional, una pena importante en un mundo dirigido por las audiencias y los followers o seguidores" (Sánchez-Gey, 2019, p. 170).

Una vez realizada la clasificación de informaciones se analizaron 229 documentos publicados durante los 55 días que componen la muestra seleccionada.

\section{Resultados}

Tras el análisis de los 229 textos que conforman el corpus de análisis de este trabajo de investigación, de forma general, se puede afirmar que el tema que más informaciones ha suscitado relacionada con bulos o informaciones falseadas ha estado relacionado con contenidos de índole política. Del total de los textos analizados, 111 son sobre este asunto, lo que supone un 48,47\% del total. En relación a redes sociales se han hallado 66 documentos que suponen el $28,8 \%$ del total del análisis y sobre las polémicas declaraciones del jefe del Estado Mayor de la Guardia Civil se han recogido en total 52 informaciones $(22,7 \%)$. 
Los gráficos e imágenes de nubes de palabras y combinación de palabras, se han seleccionado de forma que fueran lo más relevantes posible para la investigación. Por este motivo a veces se han usado unos u otras y se ha variado la frecuencia de aparición de palabras. Se exponen los resultados en orden decreciente en número de informaciones.

\subsection{Polémicas Declaraciones del Jefe del Estado Mayor de la Guardia Civil}

\subsubsection{Diario ABC}

Si se desglosan los datos de las gráficas de análisis por medios de comunicación respecto a las declaraciones del general José Manuel Santiago (que encontramos en las páginas 10, 11, 12 y 13 de este articulo) se puede observar que en el periódico $A B C$ el término que más aparece, con una frecuencia de aparición de 137 veces y encontrándose en un $85,84 \%$ de los documentos, es la palabra 'Gobierno', pero la segunda (98 veces y una frecuencia del 72,73\%) es 'bulo'. De esta forma el término bulo, que es el que prefiere utilizar el Gobierno frente a otros sinónimos, se ha incluido en la agenda diaria de este medio de comunicación ampliamente. El sinónimo 'fake' aparece 9 veces en el $15,15 \%$ de los textos. Tras la palabra bulo aparece 'Estado' que en el contexto se puede considerar sinónimo de 'Gobierno' que encabeza el ranking. En este caso aparece en 78 ocasiones y en un $75,76 \%$ de las informaciones analizadas. Significativas son las dos palabras siguientes, 'libertad' y 'expresión', la primera con un 66 de frecuencia y un 48,48\% de aparición en los documentos, mientras que la segunda le sigue muy de cerca apareciendo 57 veces en el $45,45 \%$ de los documentos.

Estos números servirían para confirmar la relación que el periódico $A B C$ establece entre las afirmaciones del general, los bulos y la defensa a la libertad de expresión. Esta correlación sería semejante a la que se ha visto en las declaraciones del Partido Popular, Ciudadanos o Vox respecto a relacionar lo dicho por el general y la libertad de expresión. La postura de los tres grupos de la oposición al respecto se ve clara en la información de Europa Press: "PP, Vox y Cs critican la pregunta del CIS sobre control de medios por pretender "poner un bozal" a libertad de expresión" (Europa Press, 2020) Un hecho en el que ahondaban los líderes políticos días después: "Casado acusa al Gobierno de "perseguir la libertad de expresión y prohibir que les critiquen": "No vamos a permitirlo" (Europa Press, 2020).

Por supuesto también aparece en gran medida la palabra coronavirus: 46 veces en el 48,48\% de los textos seleccionados.

Teniendo en cuenta que el motivo esgrimido por el ministro de Interior Fernando Grande Marlasca, desde el primer momento de la crisis, fue un lapsus: "Si esas son las expresiones que ha proferido, ha debido de ser un lapsus del general al contestar" (Pareja, 2020); esta palabra solo aparece en 21 ocasiones y en el 36,36\% en los documentos sobre lo ocurrido. Algo parecido ocurre con la palabra 'fallo' ( 7 veces en el 21,21\% de textos), que fue el término utilizado como explicación por el director del Centro de Coordinación de Emergencias del Ministerio de Sanidad, Fernando Simón, "utilizar fallos en los discursos que podemos tener, frases que decimos personas que ya estamos al límite de nuestra resistencia, para atacarnos como equipo, no es algo decente" (García, 2020). Las palabras 'error' o 'malentendido' no aparecen y 'censura' y 'ataque' solo aparecen 4 veces en el 0,09\% de documentos y 2 veces en el 3,03\% de textos, respectivamente.

Los datos extraídos indican que el día que más informaciones se publican sobre lo ocurrido en el periódico $A B C$ es el día 19 de abril de 2020, día que el general de la Guardia Civil hace las declaraciones, con siete noticias sobre lo sucedido y posteriormente el 21 del mismo mes, en que se 
publicaron 6 noticias, correspondiendo con el día después de que el general volviera a la rueda de prensa. Se sigue el tema, aunque con menos intensidad el día 20 con tres noticias, el 22 con una, el 25, 26 y 29 con otra cada día respectivamente. Por tanto, la crisis de la declaración del general se extiende durante diez días en este periódico.

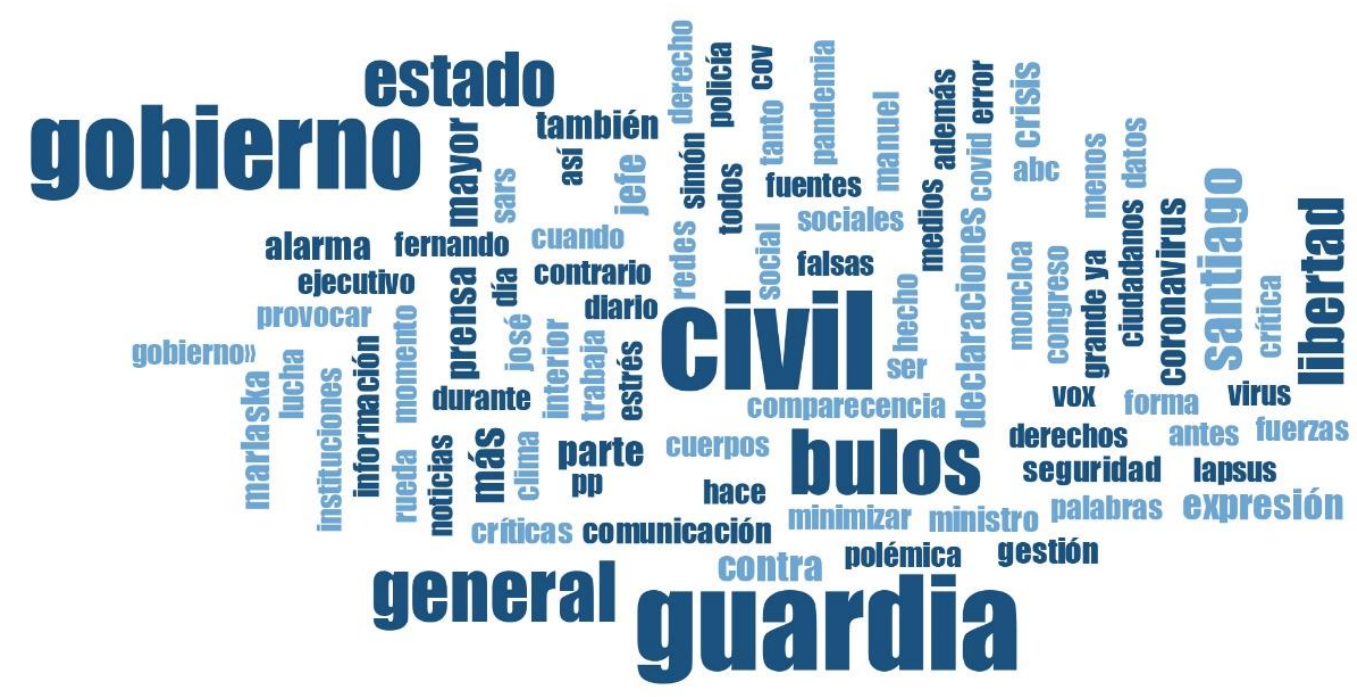

Imagen 1: Palabras más relevantes repetidas en ABC. Frecuencia 4.

Fuente: Elaboración propia con MAXQDA2020.

\subsubsection{El Mundo}

En El Mundo (8 documentos) la palabra 'Gobierno' se mantiene en las primeras posiciones, apareciendo con una frecuencia de 56 y en el $100 \%$ de los textos. Del mismo modo, la palabra 'bulo' se menciona 33 veces y en un 87,50\% de los documentos; su sinónimo 'fake', solo se menciona 5 veces en el 50\% de los documentos. También 'censura' aparece en el 50\% de lo ítem de análisis, con un 6 de frecuencia. 'Libertad' y 'expresión' aparecen como términos importantes mencionadas ambas palabras 27 veces, aunque la primera en 5 de los textos analizados y la segunda en 4 de ellos. Sin embargo 'lapsus' solo aparece en 6 ocasiones y apareciendo en 3 de las 8 noticias analizadas. El término 'error' solo aparece una vez en todo el análisis, aunque también se halla 'errores' en 7 ocasiones mencionada en 2 documentos. La palabra 'coronavirus' está en el 100\% de los textos con un 30 de frecuencia.

Se observa cierto paralelismo en el tratamiento que hacen de la información $A B C$ y $E l$ Mundo, a pesar de que cuantitativamente hay una gran diferencia: en el periódico $A B C$ se incluyen 33 noticias sobre las declaraciones del general, mientras que en El Mundo solo se recogen 8. 
RLCS, Revista Latina de Comunicación Social, 78, 359-391

[Investigación] DOI: 10.4185/RLCS-2020-1481| ISSN 1138-5820| Año 2020

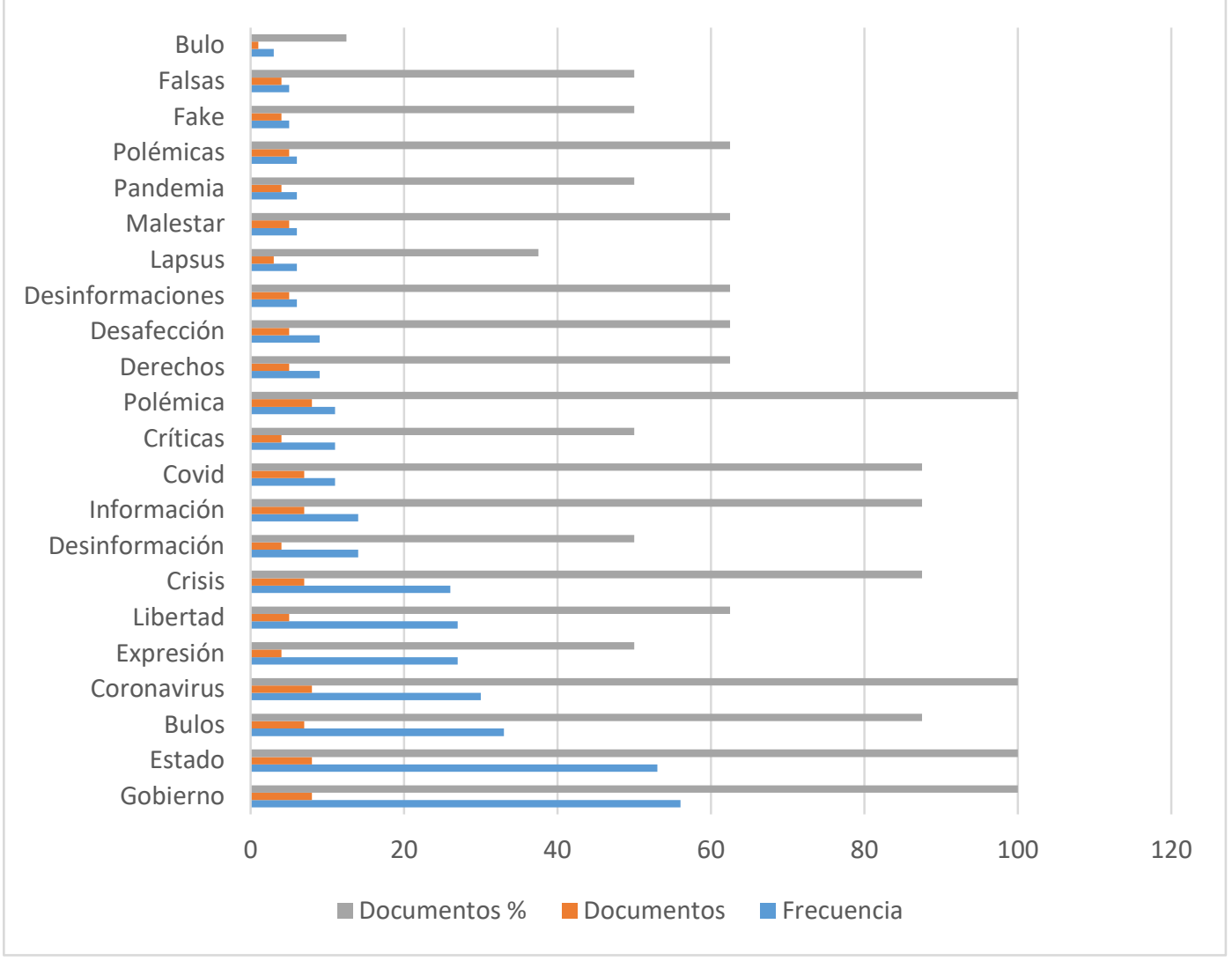

Gráfico 1: Palabras más relevantes repetidas en El Mundo. Fuente: Elaboración propia con MAXQDA2020.

\subsubsection{El País}

La observación de las tablas extraídas del estudio del periódico El País demuestra que los términos más utilizados son recurrentes. Entre ellos 'Gobierno' y 'Estado' con una frecuencia 31 y 30 respectivamente; apareciendo ambas palabras en el 100\% de los textos. 'Bulos' se repite con una frecuencia de 26 y en un $80 \%$ de los textos, mientras la palabra 'fake' solo está 3 veces en el $60 \%$ de las informaciones estudiadas. No obstante, la palabra 'desinformación' aparece 9 veces en un $60 \%$ de los textos y 'desinformaciones' una vez. 'Coronavirus' tiene una frecuencia de 15, apareciendo en todas las informaciones. Resulta curioso que el término 'lapsus' se encuentre 9 veces, 'errores' 4 , 'fallos' 1 .

Las palabras 'libertad' y 'expresión' tienen una frecuencia de 10 y aparecen en el $60 \%$ de los ítems. Esto indica que han tenido menos eco las declaraciones hechas por los partidos políticos que relacionaban las declaraciones del general con la libertad de expresión en este medio de comunicación respecto a los dos analizados anteriormente. También es llamativo que la palabra 'censura' baja en aparición hasta el 2 de frecuencia y un $40 \%$ de aparición y la palabra 'ataque' aparece en el 100\% de los textos, aunque solo en 6 ocasiones. 


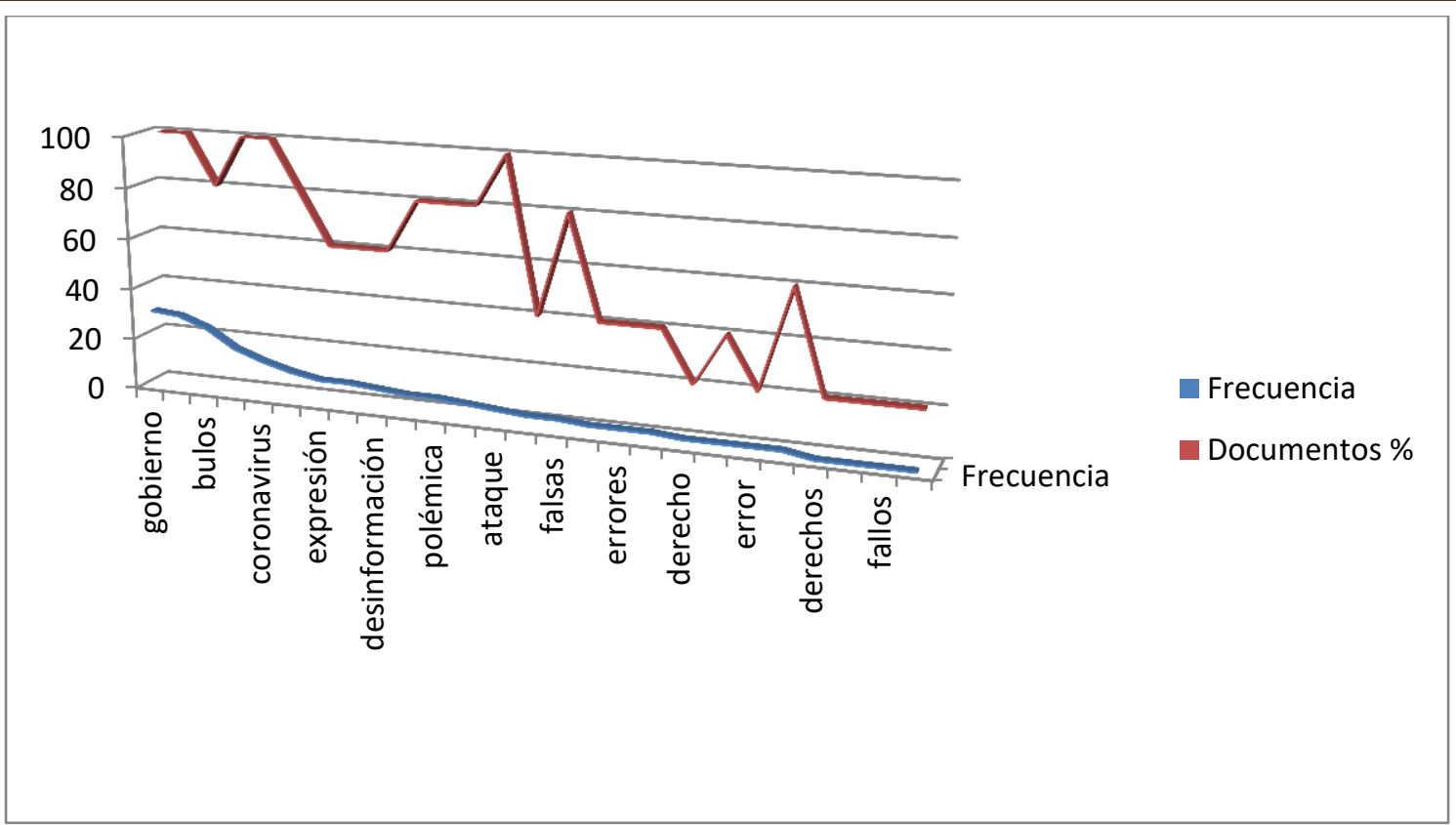

Gráfico 2: Palabras más relevantes repetidas en El País. Fuente: Elaboración propia con MAXQDA2020.

\subsubsection{EI Periódico}

En El Periódico se repiten las principales palabras en los primeros puestos y en este orden: 'Gobierno' y 'Estado', con un 31 y 30 de frecuencia y apareciendo en el 100\% de los textos. El vocablo 'bulos' aparece con un 26 de frecuencia y un $80 \%$ de aparición. 'Coronavirus' baja la frecuencia de aparición, solo 7 veces. El término 'censura' no aparece y 'ataque' solo se menciona una vez. Los términos 'expresión' y 'libertad' se dan con una frecuencia de diez y mostrándose en el $60 \%$ de los textos analizados, también bajando su importancia al igual que $E l$ País, respecto a $A B C$ y a $E l$ Mundo. Aquí se puede concluir que los medios con tendencia a la izquierda han establecido menos relación entre en incidente del general y la supuesta pérdida de libertad de expresión argumentada por el Partido Popular y Vox.

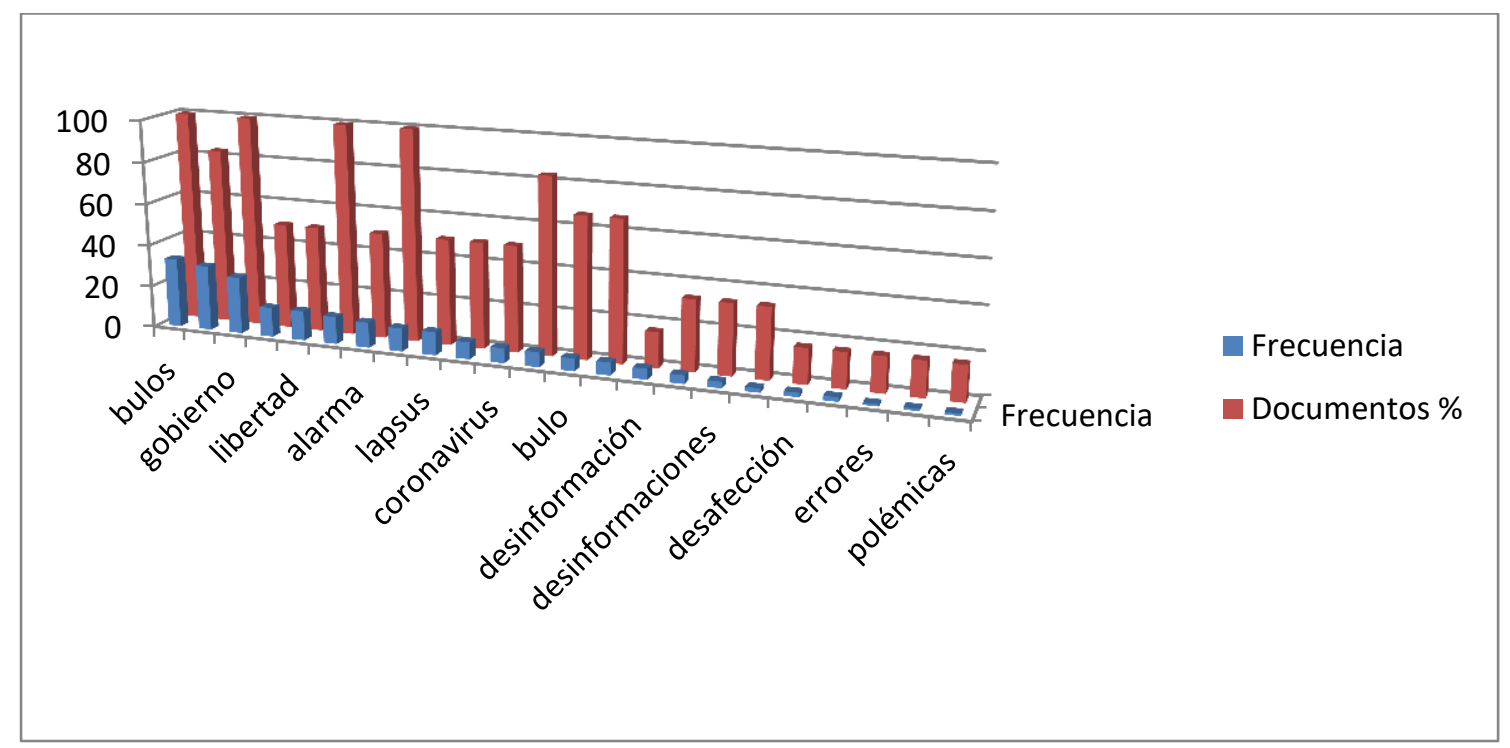

Gráfico 3: Palabras más relevantes repetidas en El Periódico.

Fuente: Elaboración propia con MAXQDA2020. 
De los datos obtenidos se puede deducir que todos los medios analizados han publicado las intervenciones oficiales acompañadas de declaraciones oficiales, fotografías e incluso vídeos. En relación al volumen, el periódico $A B C$ es el que más informaciones ha incluido sobre el tema analizado, seguido de El Mundo, después El Periódico y por último El País. Numéricamente los medios de tendencia ideológica de derecha han publicado más informaciones sobre esta materia y han hecho seguimiento mayor número de días.

\subsection{Las redes sociales en las informaciones sobre COVID-19}

El cuarto parámetro es el compuesto por las noticias relacionadas con redes sociales e informaciones falseadas, destacando por novedosas las iniciativas de control para evitar la difusión de bulos. Ya se utilizaron puntualmente en torno a las últimas campañas electorales "WhatsApp quiere luchar contra los bulos: te dejará buscar en Google las imágenes que recibas para comprobar su veracidad" (Ansorena, 2020), "Así van a intentar frenar las 'fake news' las redes sociales en las elecciones del 28-A" $(A B C, 2019)$ y ahora con la crisis del COVID-19 se ha vuelto a esta idea "WhatsApp solo permitirá reenviar mensajes a una conversación para combatir los bulos" (Martínez, 2019). El hecho es que esta medida, unida a que el clima ya estaba enrarecido por la polémica del general en torno a la monitorización de la información y si eso supone una censura o si afecta a la libertad de expresión, hizo que surgieran nuevas informaciones falseadas sobre la iniciativa, sus objetivos y quién sería el organismo adecuado para decir si algo es o no bulo. Algo que ha ocasionado no solo un aumento de noticias sobre esta temática, sino que este crecimiento no ha estado exento de sesgo ideológico. Algo que queda patente en la frecuencia y el porcentaje de aparición de determinadas palabras como se ha probado en este estudio.

\subsection{1. $\mathrm{ABC}$}

Las palabras más relevantes que se deprenden del análisis de $A B C$ son: 'mensajes', 'Facebook', 'redes', 'WhatsApp', 'cuentas', 'perfiles' y 'usuarios', términos de directa relación con las redes sociales, las aplicaciones y la tecnología. Junto a estos vocablos específicos se hallan otros relacionados directamente con los primeros: 'información', 'bulos', con un $71 \%$ y un $68 \%$ de frecuencia respectivamente y apareciendo en un $65,71 \%$ de las informaciones ambos. Junto a 'bulos', con datos muy similares se sitúan: 'falsas' y 'falsos', con una frecuencia de 50 y 49 y un porcentaje del $60 \%$ y el 37,14\%. 'Desinformación' se encuentra en un $40 \%$ de los textos.

Otras palabras a destacar son 'checker', 'cheking' o 'chequear' relacionado con esas empresas que se dedican a confirmar si una información es verdadera o falsa y que han sido cuestionadas debido a que se ha difundido que serían ellas las que controlarían los mensajes según directrices del Gobierno. "La compañía tacha de 'rumores falsos' el bulo que intenta hacer creer que WhatsApp, los medios independientes de verificación de contenidos y el Gobierno están 'compinchados' para 'censurar' mensajes" (El Mundo, 2020). El bulo corrió tanto que se aconsejó la descarga de otra aplicación móvil similar a WhatsApp que es la más utilizada, en este caso Telegram, para evitar este control. Todo esto a pesar del desmentido de la empresa explica el cambio de este modo: "una vez que un mensaje ha sido compartido cinco veces, ahora solo será posible reenviar ese mensaje a otros chats de uno en uno" (Del Castillo, 2020). Lo que sí es cierto es que Facebook dueño de WhatsApp paga por verificar contenidos a Maldita.es y Newtral, cuyo papel consiste en contrastar las noticias falsas algo que no es nuevo-, sobre la pandemia y esos datos se publican en sus propias páginas, pero no hay correlación con WhatsApp ni puede filtrar los mensajes que hayan sido denunciados. WhatsApp aseguró que no es cierto que filtre información y que tampoco es posible técnicamente $(A B C, 2020)$. 
La polémica surge de que evidentemente la tendencia ideológica de Maldita.es y Newtral es conocida y las informaciones sobre esta polémica se utilizan con un claro sesgo ideológico.

En las palabras combinadas vuelven a repetirse los términos vinculados con la polémica descrita: 'redes sociales' con un 43 de frecuencia y apareciendo en el 60\% de las informaciones; 'red social' con 31 de frecuencia y el 40\%; 'mensajes reenviados' con un 17 de frecuencia y un 22,86\%; 'mensajes virales', aunque con un 6 de frecuencia y aparece en un 5,71\% de los textos.

También en posición principal, los términos relacionados con la información falseada: 'cuentas falsas,' con un 28 de frecuencia y apareciendo en el 28,57\% de los textos; 'perfiles falsos' también 28 de frecuencia y un $22,86 \%$ de aparición; 'fake news' con un dieciséis de frecuencia y un 25,71\%; 'noticias falsas' con 14 de frecuencia y $28,57 \%$.

Con asiduidad también aparecen: 'Pablo Iglesias', 'partidos políticos' y 'Pedro Sánchez'; además de otros términos como: 'checking network', 'desmetir bulos', 'fact checking' y 'fact cheking'.

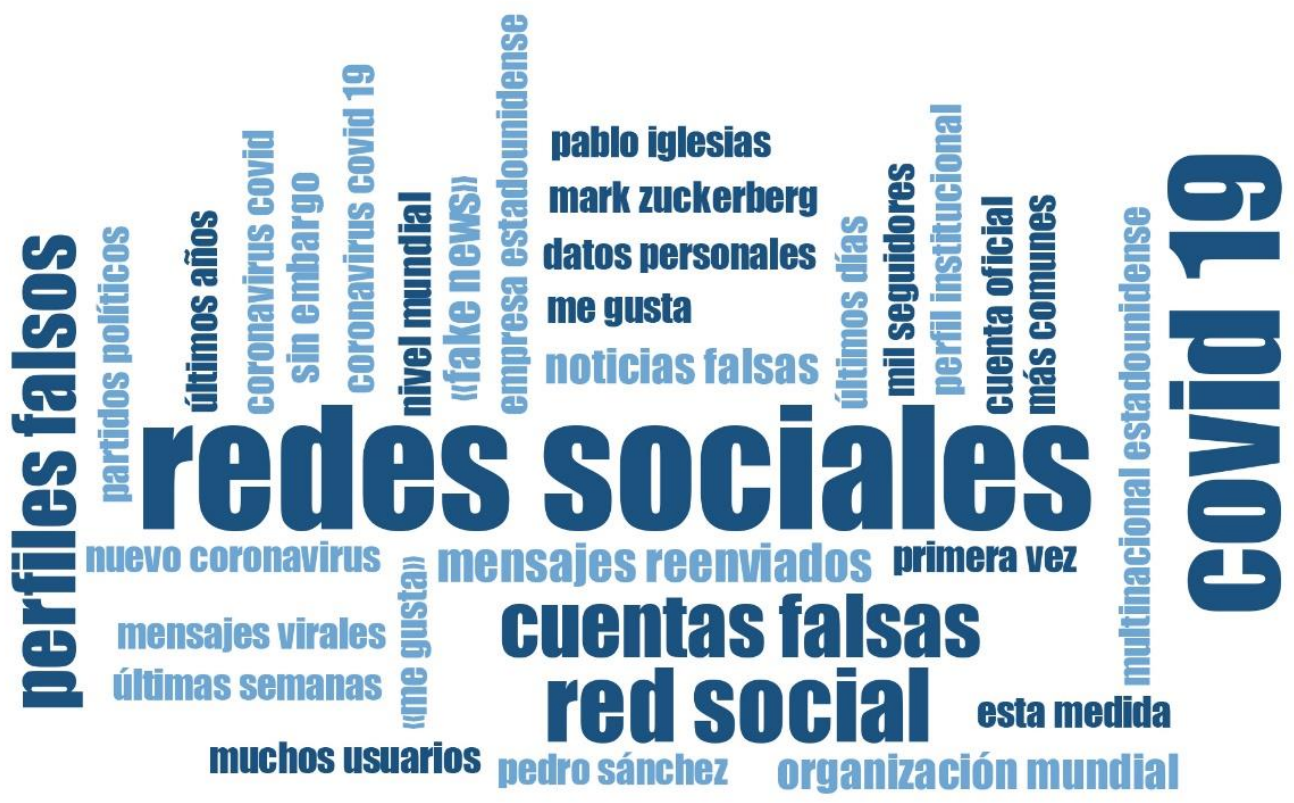

Imagen 2: Combinación de palabras sobre Redes Sociales. A partir de frecuencia 6.

Fuente: Elaboración propia con MAXQDA2020.

\subsubsection{El Mundo}

En el periódico $E l M u n d o$ se hallan palabras muy similares a las de $A B C$ como las más mencionadas. Encabeza el listado 'WhatsApp' con 39 de frecuencia y apareciendo en un $62,50 \%$ de las informaciones. 'Gobierno' es la siguiente palabra con 29 de frecuencia y un $75 \%$ de aparición. 'Falsas' se sitúa con un 25 de frecuencia y $87,50 \%$. Sí es destacable que en este medio se encuentran las palabras relacionadas con fact check y en concreto con las empresas relacionadas con Facebook y con WhatsApp y protagonistas de la polémica: 'Maldita' con una frecuencia de 23 y apareciendo en el 37,50\% de los textos; 'Newtral' con 13 de frecuencia y también 37,50\%; y, en concreto, el término 'verificadores' en el $37,50 \%$ de los documentos. 
El término 'bulo' se sitúa con una frecuencia de 22 y apareciendo en el 87,50\% de los ítems. Resulta destacable el uso del vocablo 'bot'. Bot es una aféresis de robot que se refiere a un programa informático que efectúa tareas de forma autónoma y repetitiva a través de Internet. Este término cobra relevancia porque otras de las informaciones de importancia relacionadas con redes sociales, informaciones falseadas y el Coronavirus es la aparición de cientos de perfiles falsos que afectaban a la página del Ministerio de Sanidad. Después se supo que eran fraudulentos: "Facebook atribuye las cuentas falsas que interactuaban con la página del Ministerio de Sanidad dando 'Me gusta' a sus mensajes a una red global de spam (mensajes no solicitados enviados de forma masiva con fines comerciales o publicitarios)" (Vega, 2020). Se trata de información con sesgo ideológico, aunque no se ha podido comprobar si beneficiaba a una tendencia ideológica u otra.

En las palabras combinadas uno de los términos más frecuentes es 'cuentas falsas' (15) en el 25\% de los textos. A este le siguen 'redes sociales' con 9 de frecuencia en el 62,50\% de los ítems. También aparecen las empresas de verificación con los nombres más representativos a nivel social. De esta forma aparece 'Ana Pastor' fundadora de Newtral con una frecuencia de 6 en un 12,50\% de las informaciones analizadas y 'Clara Jiménez' cofundadora de Maldita.es. Asimismo, las parejas 'cuentas falsas' e 'informaciones falsas' y 'perfiles falsos' resultan también representativas.

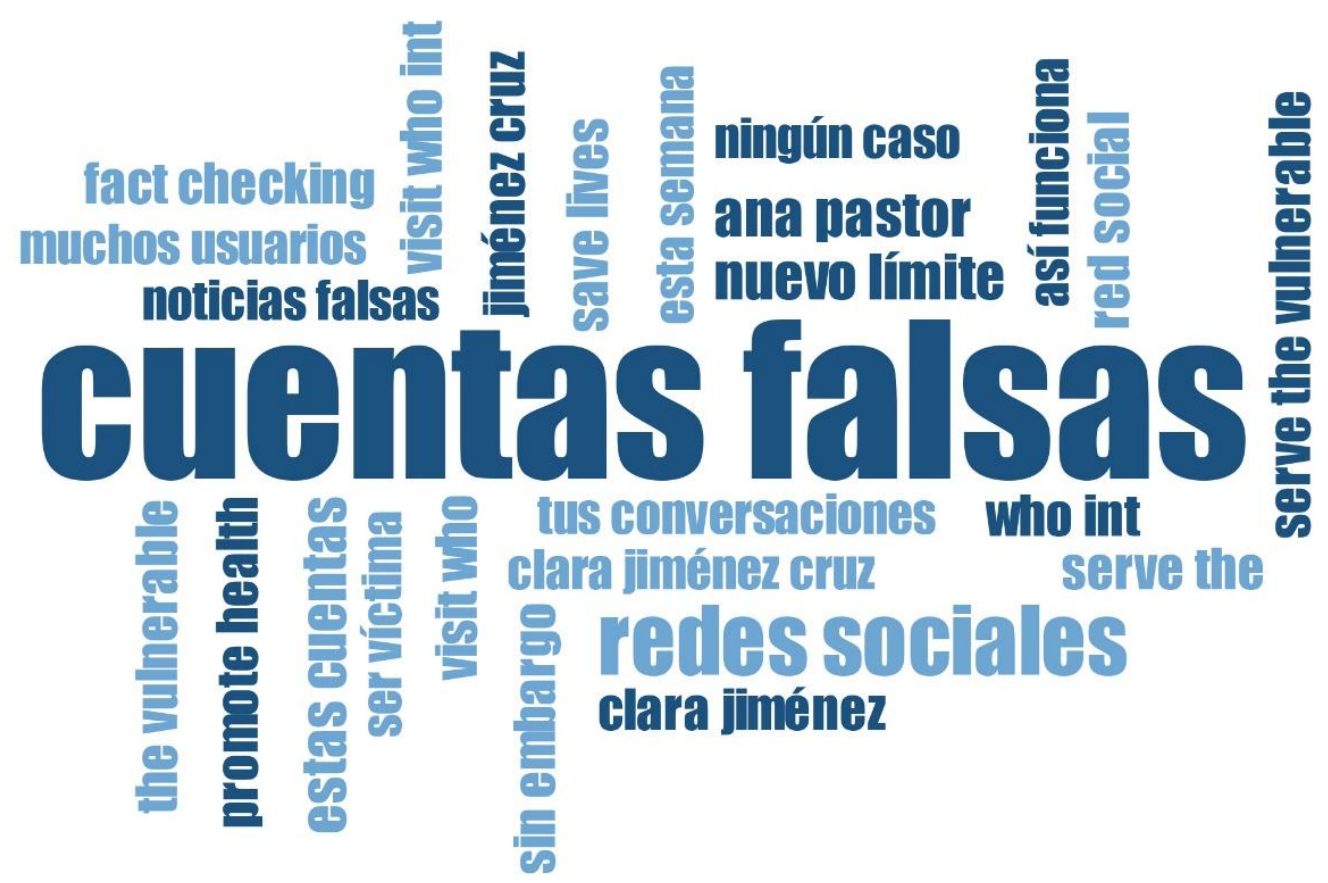

Imagen 3: Combinación de palabras sobre Redes Sociales. A partir de frecuencia 4.

Fuente: Elaboración propia con MAXQDA2020.

\subsubsection{El País}

Al analizar la frecuencia de palabras en El País se aprecia una diferencia importante. Así, aunque las palabras más repetidas son 'WhatsApp' y 'Facebook', con 54 y 53 de frecuencia, y apareciendo en un $52,94 \%$ y un $64,71 \%$ de los textos, respectivamente, los términos relacionados con la verificación de información como Maldita.es, Newtral aparecen en menor medida (4 y 1 respectivamente). Sí aparecen verificadores y sus derivados con un total de 21 veces. Así, El País informa de la polémica, pero no entra tanto a mencionar las agencias de verificación. 'Bot' también se halla con una 
frecuencia de 25 y en un $23,53 \%$ de los textos. 'Bulos' sube a un 31 de frecuencia y se encuentra en el $64,71 \%$ de documentos.

En las palabras combinadas también es destacable el cambio en la frecuencia, no parecen los nombres relacionados con las empresas de verificación, solo el concepto 'verificadores independientes', con este calificativo que lo determina, con una frecuencia de 4 y apareciendo en el $11,76 \%$ de las muestras de análisis.

También se encuentran términos relacionados con la temática de las cuentas falsas seguidoras del Ministerio de Sanidad. Por ejemplo, 'noticias falsas, 'perfiles falsos', 'cuentas altas' y 'cuentas sospechosas', con 13, 8, 7 y 4 de frecuencia y los tres primeros aparecen en un 17,65\% de los textos y la última en el $23,54 \%$.

Relacionadas con la respuesta a esta polémica de que se trataba de una actividad fraudulenta relacionada con bot de labor automática, aparecen los siguientes términos: 'actividad fraudulenta' y 'altamente reenviados' con una frecuencia de 4 y apareciendo en un 17,65\% y un 23,53\% de los textos, respectivamente.

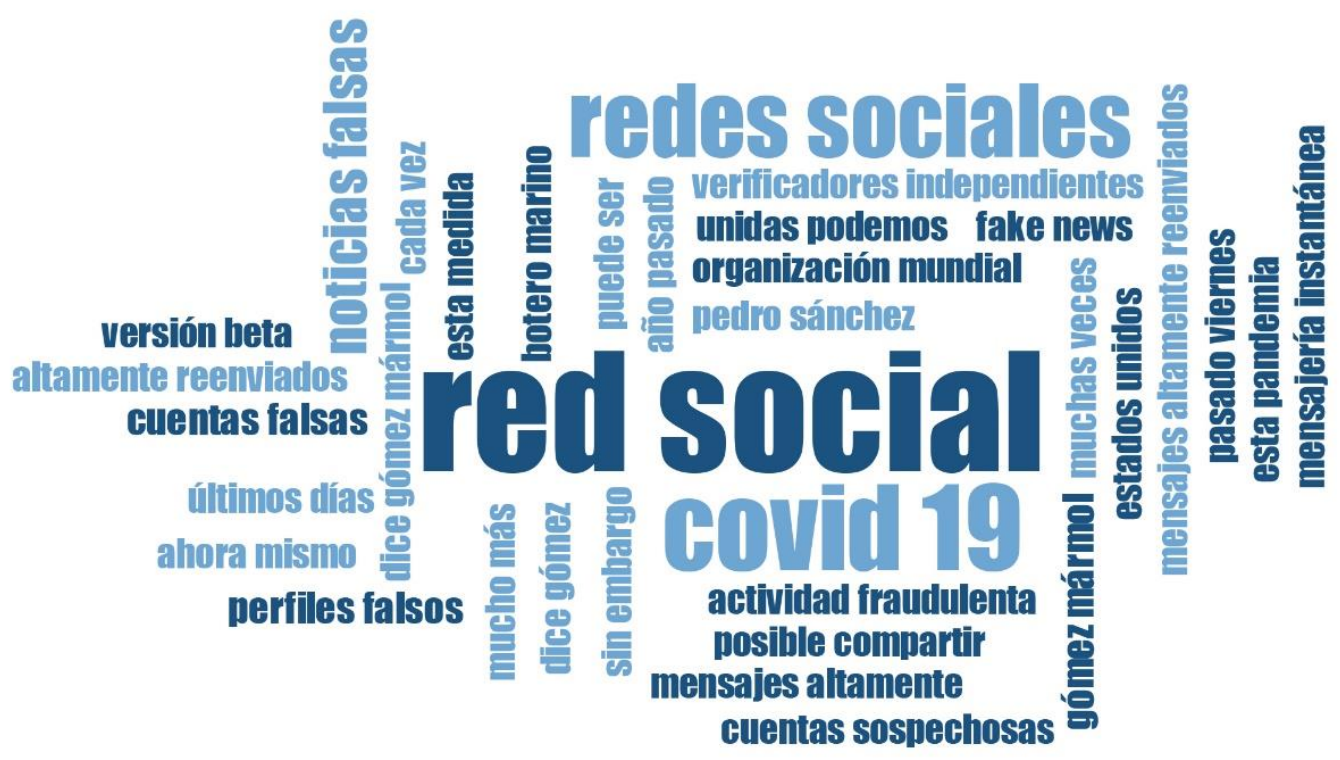

Imagen 4: Combinación de palabras sobre Redes Sociales. A partir de frecuencia 4.

Fuente: Elaboración propia con MAXQDA2020.

\subsubsection{El Periódico}

En El Periódico se aprecia una frecuencia de palabras muy similar a la El País. Entre las primeras se encuentran 'mensajes' y 'redes' con un 13 y 11 de frecuencia y apareciendo en un 33,33\% y un $66,67 \%$ de los textos. La palabra 'bulo' aparece con una frecuencia de 10, pero en el $100 \%$ de las noticias. El término 'desinformación' está 5 veces y en un 33,33\% de las informaciones analizadas. Las redes sociales más significativas: 'Facebook', 'Twitter', 'WhatsApp', están presentes en el 50\% de los documentos, en el $33,33 \%$ y en el $83,33 \%$ respectivamente. 
Respecto a las empresas verificadoras, Maldita.es no aparece, mientras que Newtral lo hace en 7 ocasiones en un 33,33\% de los documentos y la palabra 'Pastor', apellido de la fundadora de Maldita, está 5 veces en el 33,33\% de los textos.

La frecuencia de las palabras paralelas al resto de medios. La primera palabra es 'redes sociales' seguida de 'fake news' con una frecuencia de 10 y 5 respectivamente y apareciendo en un $50 \%$ y un $66,67 \%$ de las noticias estudiadas. 'Ana Pastor' se sitúa con 3 de frecuencia y 33,33\% de documentos.

Resulta destacable que se encuentre 'extrema derecha', con una frecuencia de 3 y apareciendo en el $16,67 \%$ de lo ítem. Significativo porque es un concepto que no aparece en ninguno de los otros medios estudiados.

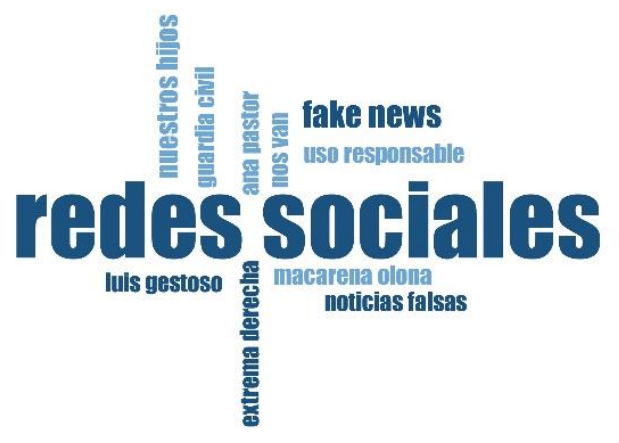

Imagen 5: Nube de palabras sobre Redes Sociales. A partir de frecuencia 4.

Fuente: Elaboración propia con MAXQDA2020.

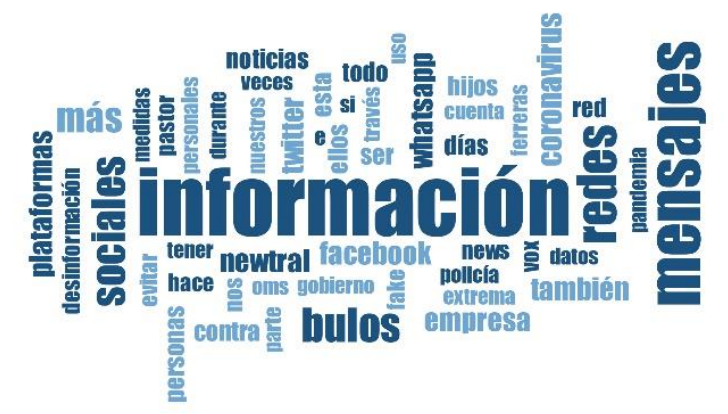

Imagen 6: Combinación de palabras sobre Redes Sociales. A partir de frecuencia 3.

Fuente: Elaboración propia con MAXQDA2020.

\subsection{Contenido político en las informaciones sobre el COVID-19}

Las informaciones con contenido político relacionadas con bulos o informaciones falseadas son las más numerosas en la muestra recogida para esta investigación. Del total de las informaciones, 229 textos analizados, 111 tienen directamente vinculación política. Por tanto, el 48,47\% de dichos textos tienen esencialmente contenido político. Cuantitativamente se aprecia una gran diferencia entre los medios de tendencia hacia la derecha y los que tienden a la izquierda. $A B C$ y $E l$ Mundo publican el $73,83 \%$ del total de las informaciones con contenido político mientras que El País y El Periódico solo recogen el $26,13 \%$. La diferencia es significativa, sobre todo teniendo en cuenta que en el 
momento en que se realiza este trabajo de investigación en el Gobierno central y, por tanto, con responsabilidad directa en la crisis, se encuentran partidos de izquierda.

A su vez, en este bloque el tema que más discusión ha creado y donde más ha destacado el concepto de 'bulo' y ha se ha dado una mayor polaridad ideológica ha sido sobre la encuesta del CIS, ya que generó una gran polémica la pregunta sobre si había que mantener "libertad total" de información sobre el coronavirus. Un hecho que entronca directamente con el control de noticias falsas por parte de los poderes públicos y, por tanto, con las polémicas declaraciones del general y las redes sociales, analizadas con anterioridad. En concreto la pregunta del CIS era: "Pregunta 6. ¿Cree Ud. que en estos momentos habría que prohibir la difusión de bulos e informaciones engañosas y poco fundamentadas por las redes sociales y los medios de comunicación social, remitiendo toda la información sobre la pandemia a fuentes oficiales, o cree que hay que mantener libertad total para la difusión de noticias e informaciones?" (CIS, abril 2020, p. 8).

\subsection{1. $\mathrm{ABC}$}

Entre las palabras con más presencia según su frecuencia y porcentaje de aparición en $A B C$ se encuentra 'Gobierno' (204 veces en el 77,55\% de los textos). Por debajo en reiteración aparece el apellido 'Sánchez' con clara relación al Gobierno ya que está señalando al presidente. La siguiente palabra es 'bulo' con una frecuencia de 63 y saliendo en un 53,6\% de las informaciones seleccionadas. Muy cerca se halla el concepto 'Estado' y a continuación, el protagonista de una de las mayores polémicas políticas, exceptuando el caso del general ya expuesto, que es la encuesta del CIS, con una frecuencia de 56 y apareciendo en un $28,57 \%$ de las informaciones. Relacionada con esta polémica el vocablo 'barómetro' con 13 de frecuencia y 14,29\% de aparición en los contenidos y también el apellido 'Tezanos' con una frecuencia de 40 y un porcentaje de aparición del 26,53\%.

Señalando las referencias a partidos políticos el primero en menciones es 'PP' (51) en el 34,69\% de los textos; el siguiente es 'VOX' con una frecuencia de 42 y un 26,5\%; el tercero 'Podemos' (41 de frecuencia y $32,65 \%$ de los textos); después 'PSOE' con un 34 de frecuencia y 30,61\%; y por último 'Ciudadanos' con 20 de frecuencia en el 26,53\% de ítems. No obstante, además de estas relaciones directas también aparecen términos como 'Iglesias' que tiene vinculación directa con 'Podemos', 'oposición', 'ejecutivo', 'congreso', 'ministro', 'Moncloa', 'comisión', 'izquierda', 'política', 'presidente' etc.

La palabra 'libertad' también aparece bien situada en la tabla con una frecuencia 41 y un porcentaje de aparición del 28,57\%.

Dentro de las palabras combinadas destacan las formadas por nombre y apellido de diferentes protagonistas políticos. Entre estos, se encuentra 'Pedro Sánchez' con un 29 de frecuencia y encontrándose en el 36,73\% de los textos; en el cuarto lugar 'Díaz Ayuso', referencia a la presidenta de la Comunidad de Madrid, del Partido Popular; 'Grande Marlaska', apellidos del ministro del Interior del Partido Socialista, se sitúan con un 8 de frecuencia y un 12,24\%; 'Pablo Iglesias', nombre y primer apellido del ministro de Derechos Sociales, de Podemos, con 7 de frecuencia y un 10,20\% de aparición y 'Félix Tezanos', presidente del CIS, con 6 de frecuencia y 12,24\%.

Además de estos nombres en las combinadas es reseñable la frecuencia y el porcentaje de aparición de la unión de palabras como 'redes sociales', siguiendo a 'Pedro Sánchez en la cúspide, con un 21 de frecuencia y viéndola en un 24,49\% de los textos; 'Unidas Podemos' con 17 de frecuencia y $22,45 \%$. Le siguen 'Gobierno central', 'guardia civil' y 'crisis sanitaria'. Destacable la unión 'noticias falsas' con 9 de frecuencia y 12,24\% de aparición en los documentos seleccionados. 'Bulos' y 'bulos e información' son menos frecuentes, al igual que 'fuentes oficiales'. 


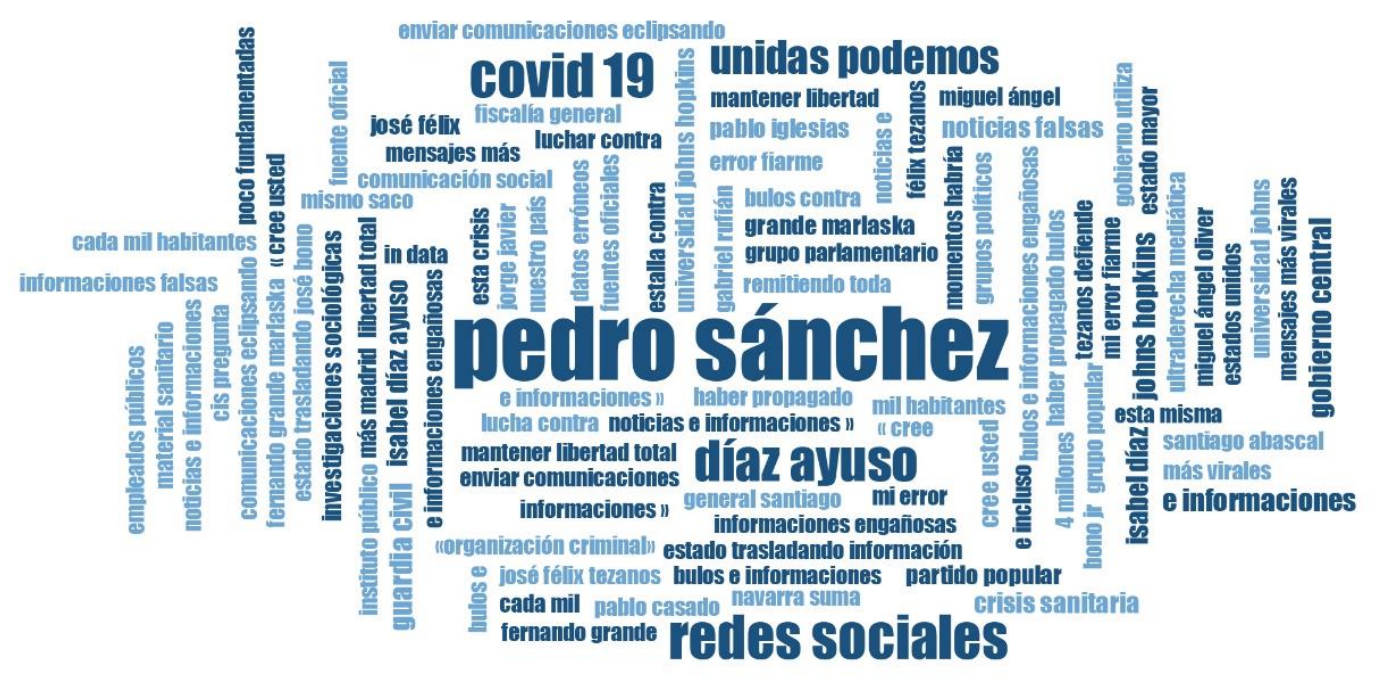

Imagen 7: Combinación de palabras sobre política. A partir de frecuencia 4. Fuente: Elaboración propia con MAXQDA2020.

\subsubsection{El Mundo}

En el periódico El Mundo, aunque 'Gobierno' esté de nuevo el primero con 188 de frecuencia y 90,91\% de presencia, 'mascarillas' aparece 113 veces en el 39,39\% de los textos, seguida de 'sanidad' con 106 de frecuencia y 60,61\%, o el concepto 'test' con 61 de frecuencia y un 36,36\%. Estas tres últimas palabras demuestran la importancia de las mismas en el contexto de la crisis sanitaria. Sin embargo, la palabra 'bulos' solo aparece con 24 de frecuencia y presentándose en un $30,30 \%$ de los textos estudiados; mientras que su sinónimo 'fake' si se halla con más frecuencia (40) y $51,52 \%$ de presencia. 'Muertos' y 'fallecidos' son también términos significativos.

En cuanto a los partidos políticos, 'PP' aparece 42 veces en el 30,3\% de los ítems (Partido Popular aparece otras 4 veces en el 9\% de los textos), 'PSOE' en 31 ocasiones en el 27,27\% de textos, 'Vox' con frecuencia 26 en el 18,18\% de informaciones, 'Podemos' con 21 menciones en el 33,33\% de documentos y 'Ciudadanos' que aparece 22 veces en el $42,42 \%$ de los textos. Además, 'Pedro Sánchez' se menciona en el $42,42 \%$ de los textos hasta 23 veces mientras que 'Pablo Casado' solo aparece en el 15,15\% de las informaciones analizadas en 8 ocasiones. También son recurrentes las menciones a 'Grande Marlaska' y 'Díaz Ayuso', ambos en el 12\% de las informaciones (11 veces y 5 veces, respectivamente).

Palabras combinadas como 'mascarillas fake' y 'mascarillas defectuosas', la primera con un veintinueve de frecuencia y la segunda con un 15 (30,30\% y 21,21\% respectivamente) muestran un tema muy recurrente en este periódico y no en los demás como es el hecho de la compra de unas mascarillas, con fallos que finalmente no se podían utilizar y tuvieron que ser retiradas, por parte del Gobierno a una empresa en China. Esta información se prolongó en el tiempo y en el espacio en $A B C$, aunque fue un caso destapado por El Confidencial, medio no analizado en esta investigación. También dentro de esta unión de palabras otras reseñables son: 'crisis sanitaria', 'fuente oficial' o 'tests rápidos'. Relacionado con 'fuente oficial' se hallan: 'datos oficiales' y 'datos reales', evidentemente lo que reclama la oposición constantemente al Gobierno y aquí se vuelve a ver sesgo ideológico en la reclamación de información. 


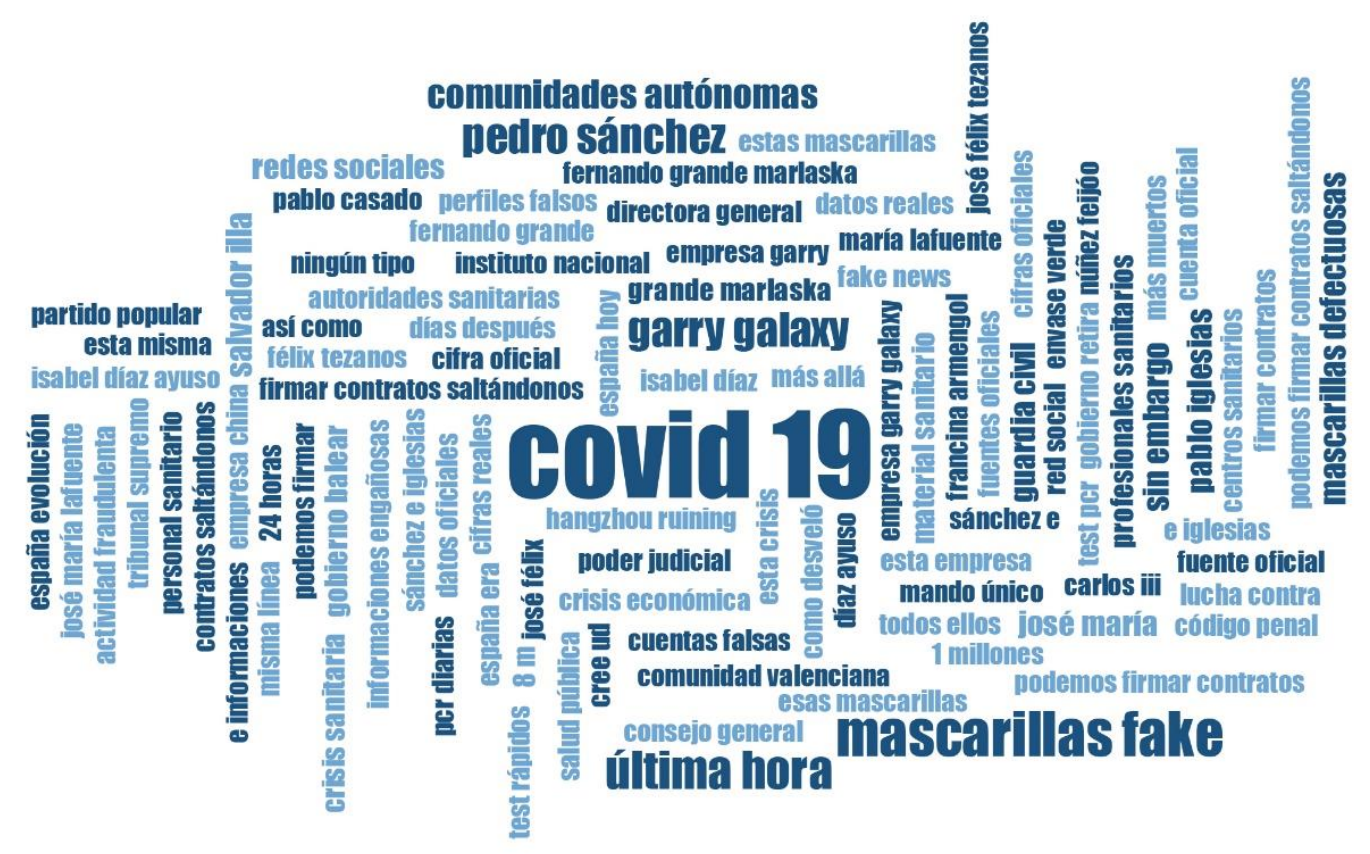

Imagen 8: Combinación de palabras sobre política. A partir de frecuencia 4.

Fuente: Elaboración propia con MAXQDA2020.

\subsubsection{El País}

Por el contrario, en El País, ciertas palabras combinadas o no existen o son muy escasas, pero destacan otras también con referencia a los temas abanderados por cada ideología en esta crisis. Así, 'Unidas Podemos' con un 28 de frecuencia y apareciendo en el 42,11\% de las noticias, seguida de 'redes sociales' con un 21 de frecuencia y un 47,37\%, 'Díaz Ayuso', después, 'material sanitario' y 'Pedro Sánchez'. Frente a esa reclamación de información, en este medio se encuentran otras uniones de palabras evaluables como 'organización criminal', con un 10 de frecuencia y $21,05 \%$ y 'extrema derecha' con 7 de frecuencia y un $21,5 \%$.

En relación a las informaciones falsas también hay términos combinados muy frecuentes que señalan la postura del Gobierno y el reflejo que este medio hace de esta. Así en la cabecera tras 'Unidas Podemos' encontramos 'redes sociales' con un 21 de frecuencia y apareciendo en un 47,37\% de las informaciones, 'noticias falsas', 'fuentes oficiales', 'informaciones engañosas', 'injurias y calumnias' y 'fake news'. Estas palabras apoyan a los temas más importantes de esta pandemia sobre informaciones falsas, la defensa sobre la acusación de oscurantismo, los bulos a través de redes sociales contra el Gobierno, la polémica sobre las declaraciones del general y la monitorización de informaciones, la crítica respecto a la búsqueda intencionada de apoyo a través de la encuesta del CIS para conseguir poder frente al control de la información, entre otros. Todos estos asuntos se observan en lo más alto de la tabla.

En la frecuencia de palabras simples encontramos también resultados claros 'bulos' con 49 de frecuencia y un $73,68 \%$ de aparición y seguido por 'VOX' con 47 de frecuencia y el mismo porcentaje. 'Gobierno' sigue en el inicio de la tabla en el puesto tres con un 86 de frecuencia y apareciendo en el $100 \%$ de los textos. Otros partidos políticos aparecen con menor frecuencia como 
'PP' con 24 menciones, 'PSOE' con 17 o 'Ciudadanos' y 'Podemos', curiosamente los más mencionados tras Vox, con 31 y 33 menciones, respectivamente.

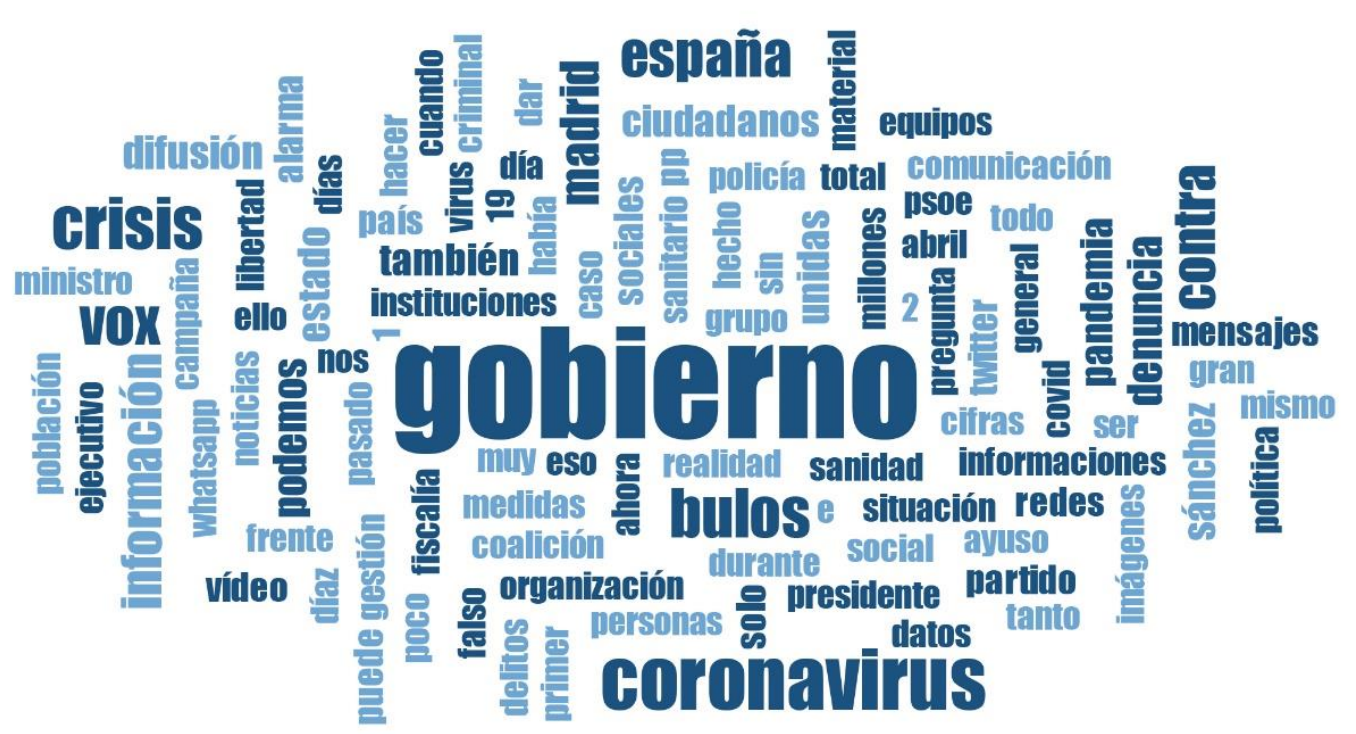

Imagen 9: Nube de palabras sobre política. A partir de frecuencia 4.

Fuente: Elaboración propia con MAXQDA2020.

\subsubsection{EI Periódico}

Por último, en El Periódico en los textos relacionados con política e información falseada 'bulo' solo aparece en 10 ocasiones, pero en un $40 \%$ de los textos. La referencia a partidos políticos es escasa: 'Podemos' (11), 'Vox' (7), 'PP' (3), 'PSOE' (3) y 'Ciudadanos' (2). Resulta significativa la presencia de los términos 'derecha' y 'falange', 4 veces cada uno de ellos.

Más representativo, en este caso, el análisis de las palabras combinadas. 'Redes sociales' con un 11 de frecuencia y apareciendo en el 50\% de los textos, seguida de 'Pedro Sánchez' con ocho de frecuencia y en un sesenta por ciento de los textos. Llamativo es el uso del binomio 'stop confinamiento', con un 8 de frecuencia y encontrándolo en un 10\% de las informaciones. Aunque la cantidad es pequeña en el resto de los medios analizados este concepto no aparecía. Se trata de un término que tanto El País como El Mundo definen como un movimiento de extrema derecha. Además, aparece 'extrema derecha' con un 4 de frecuencia y un 10\% de aparición. De nuevo se halla en el uso de las palabras el sesgo ideológico, tanto en la frecuencia como en el porcentaje de aparición. 


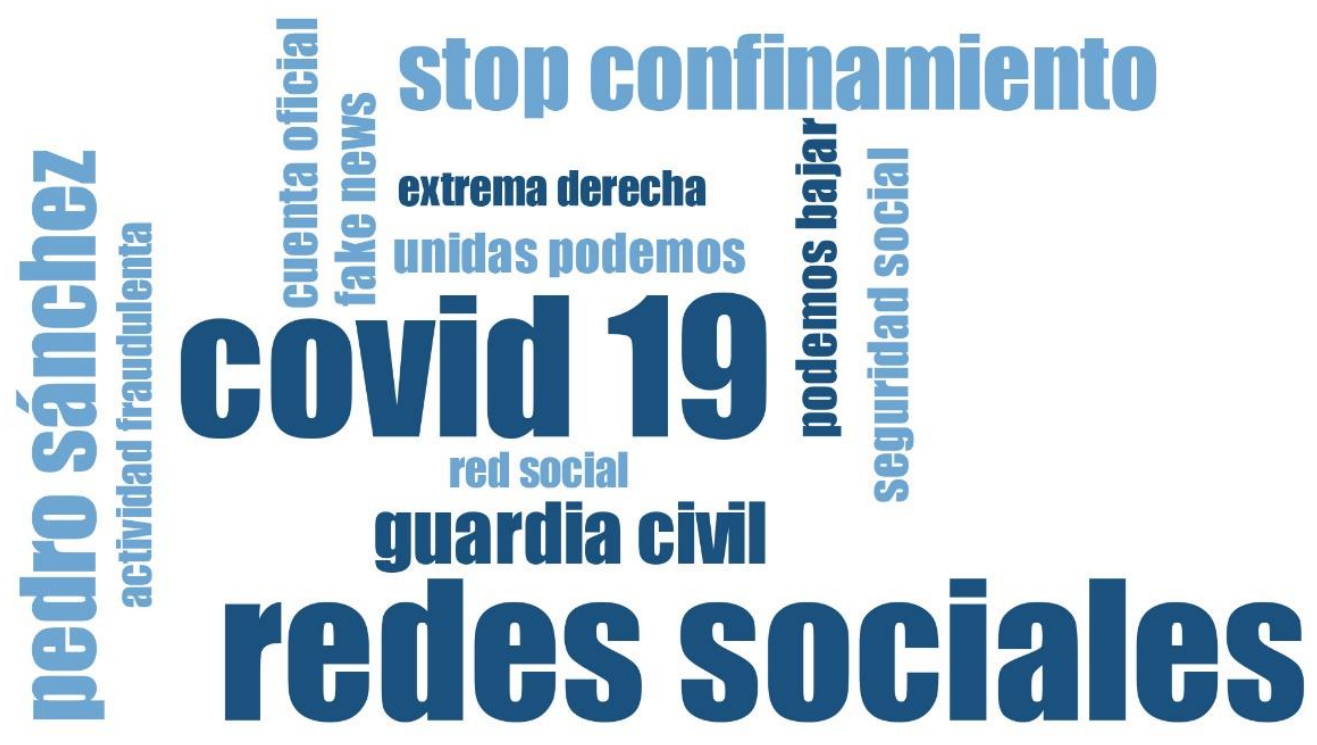

Imagen 10: Combinación de palabras sobre política. A partir de frecuencia 4.

Fuente: Elaboración propia con MAXQDA2020.

Estableciendo una comparativa de la aparición de los diferentes partidos políticos en las informaciones sobre bulos y fake news, observamos que, en general, $A B C$ es el medio que más menciona a los partidos políticos y el que menos El Periódico. $A B C$ y El Mundo son los medios que más mencionan a 'PP' mientras que curiosamente el medio que más menciona a VOX es El País. También resulta destacable que El Periódico sea el medio que más menciona a VOX y Podemos y que estos partidos políticos son también los más mencionados por El País. De hecho, este último medio al partido que menos menciona es al PSOE y menciona más a Ciudadanos que al PP. Este hecho puede tener varias lecturas, por un lado que El País no quiere que el nombre del PSOE se relacione en gran medida con la crisis de la pandemia y, por otro, que se centra más en destacar el papel de VOX y Podemos en la misma.

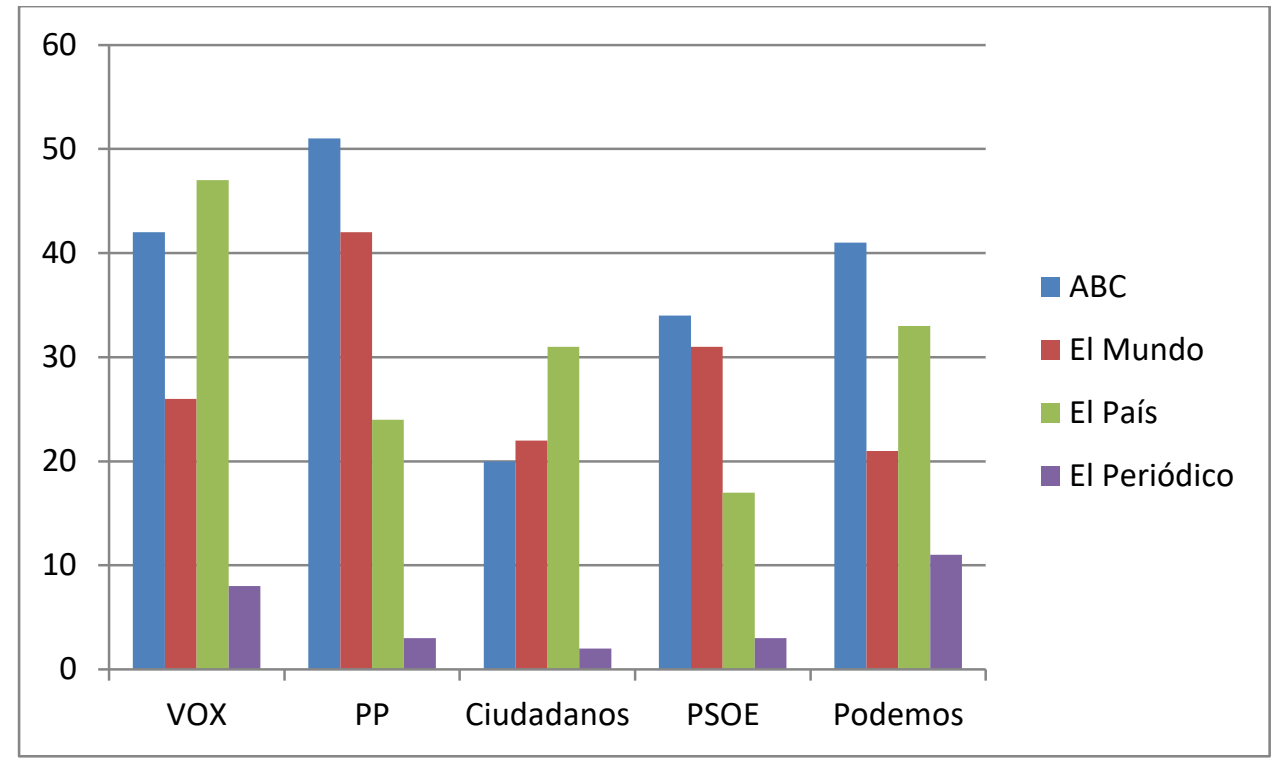

Gráfico 4: Menciones de los partidos políticos por los medios.

Fuente: Elaboración propia 
Tras el análisis de los periódicos objeto de estudio (ABC, El Mundo, El País y El Periódico), se constata que las informaciones en las que aparecen bulos o informaciones falseadas en relación con la información política son las más numerosas cuantitativamente. Además, es en el análisis de la política y las fake news donde mayor diferencia en el número de textos se halla. En el periódico $A B C$ se cuantifican 49 noticias donde lo que más prioriza es el contenido político, en El Mundo, 33; en El País, 19 y en El Periódico, 10. Resulta destacable que en los medios de tendencia ideológica a la derecha se han publicado el $73,87 \%$ de las informaciones de mayor contenido político, frente a los medios de izquierda con solo un $26,13 \%$.

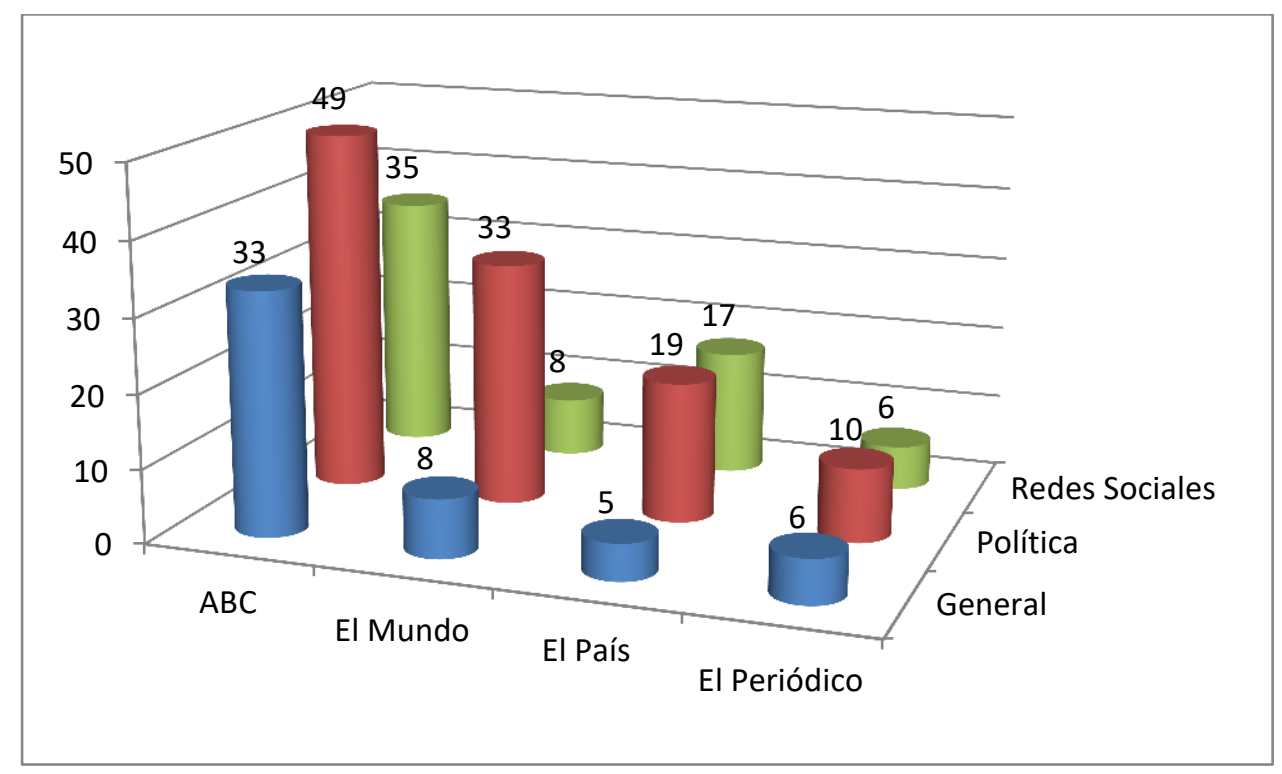

Gráfico 5: Número de informaciones por temas en los medios.

Fuente: Elaboración propia

\section{Conclusiones y Discusión}

Estos datos reflejan las tendencias de unos medios y otros, mientras que los medios con una ideología más cercana al Gobierno intentan no ahondar en las informaciones que, por contenido, pueden afectar políticamente al partido en el poder, los medios situados en la ideología opuesta entran más en el debate político de la pandemia.

En el ámbito cualitativo también quedan marcadas las diferencias en este ítem. Si se analizan las palabras que tienen mayor frecuencia y porcentaje en el periódico $A B C$ son las relacionadas con la polémica pregunta del CIS sobre el control de los bulos. Se trata de un tema que perjudica a los partidos en el Gobierno y beneficia a los que no lo están. No es una postura observada exclusivamente en el periódico $A B C$. En El Mundo, también de tendencia a la derecha, las palabras más repetidas han tenido vinculación con la crisis de las mascarillas fraudulentas. Un contenido que igualmente tiende a afectar negativamente a los partidos en el poder y ayudan a fortalecer a la oposición política. Ambos temas han sido prolongados tanto en el número de informaciones y también en el número de días en que se han publicado contenidos sobre ellos en los medios ideológicamente de derecha.

Si se tienen en cuenta las palabras más asiduas y en mayor porcentaje, en El País se detecta que no coinciden con las anteriores y cuando han tratado los temas CIS y mascarillas, ha sido de forma breve, publicando menor número de textos sobre ellos que los otros periódicos analizados. Asimismo, las palabras escogidas demuestran un enfoque muy distinto. Entre las más frecuentes 
'calumnias', 'injurias', 'información engañosa', 'fuentes oficiales', que presentan una postura de defensa al Estado frente a las dos polémicas suscitadas. Es más, la utilización del término 'bulo' aparece utilizado junto a 'Vox', no respecto al Gobierno, algo que no sucede en los dos medios anteriormente citados.

Por último, incluyendo la variante de El Periódico, este se limita a la cobertura de los dos temas destacados en los periódicos $A B C$ y $E l M u n d o$, pero de forma escueta. Señalar que entre las palabras más repetidas aparecen dos no incluidas en ninguno de los anteriores medios; 'Stop confinamiento' y 'extrema derecha'. En el uso de estos términos también se percibe el sesgo ideológico del medio en cuestión.

Con estos datos se puede concluir que, dependiendo de la ideología del medio en cuestión, la información se cuenta de forma diferente -escogiendo unos términos u otros- y se dedican más o menos textos y espacio al tema, beneficiando a los partidos con una tendencia ideológica afín y perjudicando a quienes no piensan igual.

Estas diferencias entre medios también se perciben en otra de las temáticas estudiadas. En la polémica por las declaraciones realizadas por el jefe del Estado Mayor de la Guardia Civil, el general José Manuel Santiago, es destacable que en todos los medios utilizados se dio la información de lo que el general dijo y las reacciones posteriores. Sin embargo, el seguimiento y el enfoque fueron muy distintos. Mientras que en un primer momento todos expusieron lo sucedido, porque era claramente noticiosa la polémica generada, $A B C$ y $E l$ Mundo incluyeron durante más días informaciones sobre lo ocurrido. Entre estas noticias se puede ver cómo el día después de las polémicas declaraciones, $A B C$ titulaba "La Moncloa estudia que los responsables policiales y del Ejército no participen en las ruedas de prensa" (S.E., 2020) y también publica la noticia "El Gobierno desautoriza al jefe del Estado Mayor de la Guardia Civil sin que la oposición crea su versión" (Muñoz, 2020). Es más, seis días después también $A B C$ señalaba el cambio de formato de las ruedas de prensa del Gobierno: "Policía y Guardia Civil dan por hecho que el Gobierno les retirará de las ruedas de prensa de La Moncloa" (Morcillo, 2020). Con este titular se aviva la polémica cuando en el interior del texto se indica que era algo ya sabido: "fuentes gubernamentales ya barajaban desde hace al menos dos semanas cambiar ese formato para que solo dieran explicaciones los portavoces de Sanidad y Transportes, pero la polémica suscitada por las palabras del general José Manuel Santiago motivó que se retrasara la decisión. No se quería vincular dicha polémica sobre minimizar las críticas al Gobierno con el cambio de modelo" (Morcillo, 2020).

El periódico El Mundo mantiene una línea similar, sigue dándole cobertura a todo lo relacionado con la polémica y, por ejemplo, en el caso del cambio de las ruedas de prensa el titular es el siguiente: "Moncloa pone fin a las comparecencias diarias de uniformados que informaban de la gestión del Covid-19". Y subtitula "Las ruedas de prensa del equipo técnico, primeras víctimas de la orden de Interior sobre la monitorización de informaciones contra el Gobierno" (Lázaro, 2020).

Por lo contrario, El Periódico incluye en sus páginas el cambio de modelo, pero no lo incluye en el titular, no relaciona el hecho inicialmente con lo sucedido con el general y cuando al final del texto lo menciona destaca en negrita que la reforma "estaba prevista antes de esta semana por la paulatina pérdida de octanaje de la comparecencia” (Fernández, 2020).

En el caso de El País, que es el que menos noticias contiene sobre la polémica, no llega a publicar la información como noticia independiente.com. 
Si se suman las noticias que difunden los medios de comunicación de tendencia ideológica de derecha sobre el altercado en relación con los de tendencia a la izquierda, se observa que los primeros dieron un $78,9 \%$ de las informaciones mientras que los segundos solo publicaron el $21,2 \%$ del total.

Dar más o menos cobertura a un asunto, en este caso tiene relación directa con la ideología del medio y las consecuencias políticas del tema. Sin embargo, incluir y priorizar en un titular un dato que dentro del texto se desmiente, es deontológicamente criticable y además es un reflejo de la actual lucha por los likes o clickbait en periodismo por encima de la veracidad de la información. Los titulares de clickbait crean una llamada "brecha de curiosidad", lo que aumenta la probabilidad de que el lector haga clic en el enlace de destino para satisfacer su curiosidad. La motivación del clickbait suele ser la tasa de clics y los ingresos publicitarios resultantes. Incluso aunque no todas las noticias falsas pueden incluir titulares de clickbait, los titulares específicos de clickbait podrían servir como un indicador importante y se pueden utilizar para ayudar a detectar noticias falsas (Shu et al., 2017).

A pesar de todo esto, tras el análisis de los textos se puede apreciar que el Gobierno, en su estrategia de comunicación, sí ha querido acabar con estos bulos, ya que nunca ha negado la afirmación del general. Ni siquiera el protagonista se desdijo. Ante la polémica, la respuesta de Santiago fue "perseguimos los bulos, no la crítica política" y aseguró que trabajan con un "escrupuloso respeto a la libertad de expresión",. No obstante, otros han señalado esta medida como presunta censura por parte del Gobierno y, por tanto, como un ataque a la libertad de expresión. En este sentido una lucha para "proteger" de la mentira a los ciudadanos, se convertía mediáticamente en un supuesto ataque a un derecho fundamental recogido en la Constitución Española.

Esta variable además se relaciona con otra incluida que ha sido analizada en el parámetro bulos con implicación política. Se trata del caso de la pregunta realizada por el Centro de Investigaciones Sociológicas (CIS): “¿Cree usted que en estos momentos habría que prohibir la difusión de bulos e informaciones engañosas y poco fundamentadas por las redes y los medios de comunicación social, remitiendo toda la información sobre la pandemia a fuentes oficiales, o cree que hay que mantener la libertad total para la difusión de noticias e informaciones?" (CIS, abril 2020, p. 8). Del mismo modo las informaciones sobre este aspecto se han utilizado ideológicamente apoyando o criticando negativamente la postura del Gobierno.

Asimismo, en relación al parámetro de las informaciones sobre redes sociales como difusoras de bulos sobre el coronavirus también queda demostrado que existe sesgo político. Con los datos extraídos queda patente que los partidos políticos se han acusado mutuamente de difundir bulos y noticias falsas durante el Estado de Alarma y las informaciones falsas se han colado en las agendas de los medios tradicionales.

Sobre redes sociales, las informaciones más numerosas han sido las relacionadas con la noticia de que WhatsApp iba a controlar los mensajes para combatir bulos. Una vez más se presenta un sesgo ideológico. Por ejemplo, la información de $A B C$ : "Temor a la censura ante la decisión de WhatsApp de limitar los mensajes reenviados" (Sánchez, 2020), incluye dos palabras 'temor' y 'censura', que nada tienen que ver con la versión oficial de la aplicación. Este medio, en el cuerpo de la noticia señala entre las empresas que verificarán los datos y decidirán si es bulo a Newtral y Maldita.es. Con ello generan una sensación de duda en la verificación, puesto que, aunque ambas se autodefinen como 'organismos independientes', poseen una línea ideológica determinada que podría desvirtuar el concepto de verificación. Este hecho también queda patente en las palabras utilizadas y su frecuencia en cada periódico. 
Quizá la línea editorial de $A B C$ ha sido la que más fielmente ha quedado reflejada en las informaciones sobre el COVID-19. Ha sido el medio que más tiempo y espacio ha dedicado a los temas que podían perjudicar a los partidos en el poder. Se trata de una crisis que tiene que resolver el Gobierno, de ideología de izquierda, por tanto, dar más cabida a un tema que puede perjudicar al partido en el Gobierno beneficia por contraposición a los partidos en la oposición.

Estas conclusiones coinciden con los datos extraídos de El Mundo. Por tanto, numéricamente los medios de tendencia ideológica de derecha han publicado más informaciones sobre bulos relacionados con política, con las polémicas declaraciones del General y sobre la difusión a través de redes sociales y han hecho el seguimiento un mayor número de días. Más extensión en el tiempo significa también que los lectores mantengan presente ese dato, supuestamente negativo, sobre el Gobierno más tiempo. Por el contrario, el hecho de que un medio deje de publicar información, puede hacer que se suavicen las opiniones contrarias a la gestión gubernamental.

Por tanto, los medios de comunicación tradicionales se han hecho eco de diferentes bulos o noticias falsas que han circulado por las redes durante la pandemia y lo han hecho con sesgo ideológico. No solo en su enfoque y tratamiento sino también incluyendo contenidos ideologizados de redes sociales como Twitter, Instragram o Facebook.

Todo ello hace que las hipótesis de partida hayan quedado claramente demostradas y superadas, pues diferentes actores sociales han utilizado las redes sociales para difundir bulos a favor y en contra de la gestión de la crisis por parte del Gobierno, y estos han llegado a los medios de comunicación. Los partidos políticos se han acusado mutuamente de difundir bulos y noticias falsas durante el Estado de Alarma y las informaciones falsas se han colado en las agendas de los medios tradicionales. Además, la decisión del Gobierno de acabar con los bulos, supuso un problema por las desafortunadas palabras del jefe del Estado Mayor de la Guardia Civil, fuera un lapsus o no, los medios de comunicación han utilizado ideológicamente esta supuesta 'censura' o atentado a la 'libertad de expresión’ por parte del Estado.

Este trabajo abre una línea de investigación futura sobre si se puede limitar la propagación de informaciones que se puedan considerar perjudiciales en una pandemia o si está por encima el derecho a la libertad de expresión. Por otro lado, es necesario abordar las dudas que entraña que la difusión de muchas de las informaciones falsas no tenga consecuencias legales. No obstante, tras esta pandemia existe un antes y un después sobre la concepción de lo que supone transmitir una fake news, ya no solo para los estudiosos de la Comunicación, sino para la sociedad en general, para los partidos políticos y el Gobierno, por la dimensión que le han dado incluyéndolas dentro de las prioridades comunicativas de esta crisis sanitaria.

\section{Bibliografía}

ABC Tecnología (2019). WhatsApp quiere luchar contra los bulos: te dejará buscar en Google las imágenes que recibas para comprobar su veracidad. Diario $A B C$. https://bit.ly/2TOOCcX

Allcott, H. y Gentzkow, M. (2017). Social media and fake news in the 2016 election. Journal of economic perspectives, 31(2), 211-236. http://doi.org/10.1257/jep.31.2.211

Alonso Gómez, M. (2019). Fake news: desinformación en la era de la sociedad de la información. Ámbitos. Revista Internacional de Comunicación, 45, 29-52. https://doi.org/10.12795/Ambitos.2019.i45.03 
Amorós García, M. (2018). Fake news. La verdad de las noticias falsas. Barcelona: Plataforma Editorial.

Andreu-Sánchez, C. y Martín-Pascual, M. Á. (2020). Fake images of the SARS-CoV-2 coronavirus in the communication of information at the beginning of the first Covid-19 pandemic. El profesional de la información, 29(3), e290309, 1-10. https://doi.org/10.3145/epi.2020.may.09

Ansorena, J. (2020). EE.UU. dice tener «pruebas enormes» del origen del coronavirus en laboratorio, pero no las muestra. Diario $A B C$. https://bit.ly/3dgNYNa

Azurmendi-Adarraga, A. (2005). De la verdad informativa a la "información veraz" de la Constitución Española de 1978. Una reflexión sobre la verdad exigible desde el derecho de la información". Comunicación y Sociedad, XVIII(2), 9-48. https://bit.ly/2Mbvamo

Bakir, V. y McStay, A. (2018). Fake News and The Economy of Emotions. Digital Journalism, 6(2), 154-175. https://doi.org/10.1080/21670811.2017.1345645

Balmas, M. (2014). When Fake News Becomes Real: Combined Exposure to Multiple News Sources and Political Attitudes of Inefficacy, Alienation, and Cynicism. Communication Research, 41(3), 430-454. https://doi.org/10.1177/0093650212453600

Blanco-Herrero, D. \& Arcila-Calderón, C. (2019). Deontología y noticias falsas: estudio de las percepciones de periodistas españoles. El profesional de la información, 28(3), e280308,1-13. https://doi.org/10.3145/epi.2019.may.08

Bernal-Triviño, A. \& Clares-Gavilán, J. (2019). Uso del móvil y las redes sociales como canales de verificación de fake news. El caso de Maldita.es. El profesional de la información, 28(3), e280312, 1-8. https://doi.org/10.3145/epi.2019.may.12

Brajnovic, L. (1979). El ámbito científico de la Información. Pamplona: Eunsa.

Cachán Alcolea, C. (1995). Ideología subyacente de El País, El Mundo, La Vanguardia y El Correo Español, a la luz de la información ecológica [Tesis doctoral]. Madrid: Universidad Complutense de Madrid, Facultad de Ciencias de la Información, Departamento de Periodismo II (Estructura y tecnología de la Información). https://bit.ly/3eqfM1R

Campos Freire, F. (2008). Las redes sociales trastocan los modelos de los medios de comunicación tradicionales. Revista Latina de Comunicación, 11(63), 277-286. https://bit.ly/3dbDLlf

Carrera, P. (2018). Estratagemas de posverdad. Revista Latina de Comunicación Social, n. 73, 14691481. https://doi.org/10.4185/RLCS-2018-1317

Casero-Ripollés, A. (2020). Impact of Covid-19 on the media system. Communicative and democratic consequences of news consumption during the outbreak. El profesional de la información, 29(2), e290223, 1-11. https://doi.org/10.3145/epi.2020.mar.23

Castillo-Esparcia, A., Fernández-Souto, A. B., \& Puentes-Rivera, I. (2020). Comunicación política y Covid-19. Estrategias del Gobierno de España. El profesional de la información (EPI), 29(4), 122. https://doi.org/10.3145/epi.2020.jul.19 
Cinelli, M.; Quattrociocchi, W.; Galeazzi, A.; Valensise, C. M.; Brugnoli, E.; Schmidt, A. L.; Zola, P.; Zollo, F. \& Scala, A. (2020). The COVID-19 Social Media Infodemic. ArXiv.org, 05004(1), 118. https://bit.ly/2BcfRIa

Centro de Investigaciones Sociológicas (CIS) (Abril 2020). Estudio no 3279. Barómetro especial de abril de 2020. http://datos.cis.es/pdf/Es3279mar_A.pdf

Collins, K.M.T.; Onwuegbuzie, A.J. \& Sutton, I.L. (2006). A Model Incorporating the Rationale and Purpose for Conducting Mixed-Methods Research in Special Education and Beyond. Learning Disabilities: A Contemporary Journal, 4(1), 67-100. https://tinyurl.com/y5fgvcxp

Corner, J. (2017). Fake news, post-truth and media-political change. Media, Culture \& Society, 3(7), 1100-1107. https://doi.org/10.1177/0163443717726743

Del Castillo, C. (2020). WhatsApp desmiente oficialmente la teoría de la conspiración sobre la censura de mensajes en España: "Es 100\% falso". Eldiario.es, 13 de abril. https://bit.ly/2B67VrK

Del-Fresno-García, M. (2019). Desórdenes informativos: sobreexpuestos e infrainformados en la era de la posverdad. El profesional de la información, 28(3), e280302, 1-11. https://doi.org/10.3145/epi.2019.may.02

EGM (2020). "Aumenta la lectura de prensa y revistas en papel durante el Estado de Alarma entre los Internautas". Asociación para la Investigación de Medios de Comunicación, 23 de abril. https://bit.ly/2Xclbny

Escandón Prada, V. (2019). El olvido en los tiempos de las fake news. [Tesis doctoral]. Oviedo: Universidad de Oviedo, Facultad de Derecho, Departamento Derecho Constitucional. https://bit.ly/3gHkbPY

Espinosa Sánchez, N. (2020). Censura y manipulación informativa durante las primeras semanas de la crisis del Coronavirus en España. La Razón Histórica. Revista hispanoamericana de Historia de las Ideas, 46, 39-62. https://bit.ly/2Xajkzg

Europa Press (2020). PP, Vox y Cs critican la pregunta del CIS sobre control de medios por pretender "poner un bozal" a libertad de expresión. Europa Press, 15 abril. https://bit.ly/2zGpgHl

Europa Press (2020). Casado acusa al Gobierno de 'perseguir la libertad de expresión y prohibir que les critiquen': "No vamos a permitirlo". Europa Press, 21 abril. https://bit.ly/3d7HzUq

Europa Press (2020). La OMS lanza una campaña contra la desinformación sobre el nuevo coronavirus. Europa Press, 2 de febrero. https://bit.ly/2XaVSIH

Fernández, J. (2020). Moncloa saca a los uniformados de la rueda de prensa diaria. El Periódico, 25 de abril. https://bit.ly/2XIBO9a

Fletcher, R. \& Klein-Nielsen, R. (2018). Are people incidentally exposed to news on social media? A comparative analysis. New Media \& Society, 20(7), 2450-2468. https://doi.org/10.1177/1461444817724170 
Flintham, M.; Karner, Ch.; Bachour, K.; Crewick, H.; Gupta, N. \& Moran, S. (2018). Falling for Fake News: Investigating the Consumption of News via Social Media. CHI '18: Proceedings of the $2018 \mathrm{CHI}$ Conference on Human Factors in Computing Systems, 376, 1-10. https://doi.org/10.1145/3173574.3173950

García, L. B. (2020). Aplausos para el general Santiago en la rueda de prensa tras su 'lapsus'. La Vanguardia, 20 de abril. https://bit.ly/3gwtEcx

Gómez Aguilar, M. (2010). Evolución histórica de la estructura del sistema de medios en España. En: A. Pérez-Ugena (Coord.), Materiales para la innovación en estructura de la comunicación (pp. 89-127). Madrid: Universitas.

Johnson, R.B.; Onwuegbuzie, A.J.; Turner, L.A. (2007). Toward a Definition of Mixed Methods Research. Journal of Mixed Methods Research, 1(2), 112-133. https://tinyurl.com/yxgqah6t

Kim, A.; Moravec, P. \& Dennis, A. R. (2019). Combating Fake News on Social Media with Source Ratings: The Effects of User and Expert Reputation Ratings. Journal of Management Information Systems, 36(3), 931-968. http://dx.doi.org/10.2139/ssrn.3090355

Lázaro-Rodríguez, P. \& Herrera-Viedma, E. (2020). Noticias sobre Covid-19 y 2019-nCoV en medios de comunicación de España: el papel de los medios digitales en tiempos de confinamiento. El profesional de la información, 29(3), e290302, 1-11. https://doi.org/10.3145/epi.2020.may.02

Lázaro, F. (2020). El general Santiago asegura que la Guardia Civil no actúa "contra la crítica política". El Mundo, 21 de abril. https://bit.ly/3caZokh

Lázaro, F. (2020). Moncloa pone fin a las comparecencias diarias de uniformados que informaban de la gestión del Covid-19. El Mundo, 25 de abril. https://bit.ly/2X9ZUdR

López-Borrull, A.; Vives-Gràcia, J. \& Badell, J. (2018). Fake news, ¿amenaza u oportunidad para los profesionales de la información y la documentación? El profesional de la información, 27(6), pp. 1346-1356. https://doi.org/10.3145/epi.2018.nov.17

López-García, G. (2020). Vigilar y castigar: el papel de militares, policías y guardias civiles en la comunicación de la crisis del Covid-19 en España. El profesional de la información, v. 29, n. 3, e290311, 1-12. https://doi.org/10.3145/epi.2020.may.11

Lotero-Echeverri, G.; Romero-Rodríguez, L. M. \& Pérez-Rodríguez, M. A. (2018). Fact-checking vs. Fake news: Periodismo de confirmación como recurso de la competencia mediática contra la desinformación. Index.comunicación, 8(2), 295-316. https://bit.ly/2M9LgNG

Martínez, A. I. (2019). Así van a intentar frenar las «fake news» las redes sociales en las elecciones del 28-A. Diario ABC, 29 de abril. https://bit.ly/2TP2W5o

Masip, P.; Almenar, E.; Aran, S.; Capilla, P.; Puertas, D.; Ruiz, C.; Suau, J.; Vila, P. \& Zilles, K. (2020). El consumo de información durante el confinamiento por el coronavirus: medios, desinformación y memes. Digilab, 1-24. https://bit.ly/2BcmOZK 
McGonagle, T. (2017). Fake news' False fears or real concerns?. Netherlands Quarterly of Human Rights, 35(4), 203-209. https://doi.org/10.1177/0924051917738685

Morcillo, C. (2020). Policía y Guardia Civil dan por hecho que el Gobierno les retirará de las ruedas de prensa de La Moncloa. Diario ABC, 25 abril. https://bit.ly/2TP3ok6

Muñoz, P. (2020). El Gobierno desautoriza al jefe de Estado Mayor de la Guardia Civil sin que la oposición crea su versión. Diario $A B C, 20$ de abril. https://bit.ly/2AgYKEE

Nelson, J. L. \& Taneja, H. (2018). The small, disloyal fake news audience: The role of audience availability in fake news consumption. New Media \& Society, 20(10), 3720-3737. https://doi.org/10.1177/1461444818758715

Nogales Bocio, A. \& Mancinas Chávez, R. (2014). Los diarios de referencia en el mercado de la prensa española. Propiedad, grupos mediáticos y conexiones estructurales. Correspondencia \& Análisis, n. 4, 307-333. https://bit.ly/3daSxsg

Ortega Dolz, P. (2020). Tormenta política tras declarar un general que la Guardia Civil trabaja para minimizar bulos contrarios al Gobierno. El País, 20 de abril. https://bit.ly/3cdYTWs

Ortega-Ruiz, L. G. \& Forero Forero, A. (2018). El Derecho de Rectificación en las Redes Sociales. Revista Verba Iuris, 13(40), 29-147. https://doi.org/10.18041/0121-3474/verbaiuris.40.1572

Pareja, P. (2020). La Guardia Civil admite que trabaja en "minimizar" las críticas a la gestión del Gobierno. Diario de Sevilla, 19 de abril. https://bit.ly/3ddvlK2

Parra Valero, P. \& Oliveira, L. (2018). Fake news: una revisión sistemática de la literatura. (OBS*) Observatorio, 12(5), 54-78. https://doi.org/10.15847/obsOBS12520181374

Piñas Piñas, L. F.; Villacrés, C. \& Patricio, Henán (2020). Conflicto entre la libertad de expresión y el derecho a la información veraz. Revista Digital de Ciencias Jurídicas de UNIANDES, 3(1), 4151. https://bit.ly/2Xapwau

El Mundo (2020). Whatsapp solo permitirá reenviar mensajes a una conversación para combatir los bulos. El Mundo, 7 abril. https://bit.ly/3c9baLT

Polage, D. C. (2012). Making up History: False Memories of Fake News Stories. Europe's Journal of Psychology. Vol. 8 (2), 245-250. https://doi.org/10.5964/ejop.v8i2.456

Prnoticias (2020). EGM: 'El País' sobrevive con un millón de lectores diarios. Prnoticias, 6 abril. https://bit.ly/3df3vwX

Ramonet, I. (1999). Prólogo. En: VV. AA., Sur y comunicación: una nueva cultura de la información. Barcelona: Icaria.

Rapp, D. N. \& Salovich, N. A. (2018). Can't We Just Disregard Fake News? The Consequences of Exposure to Inaccurate Information. Policy Insights from the Behavioral and Brain Sciences, 5(2), pp. 232-239. https://doi.org/10.1177/2372732218785193 
Richter Morales, U. (2018). El ciudadano digital. Fake news y posverdad en la era de Internet. Ciudad de México: Océano.

Reig, R. (2011). Los dueños del periodismo. Claves de la estructura mediática mundial y de España. Barcelona: Gedisa.

Román-San-Miguel, A. (2020). Las redes sociales como fuente de información en el periodismo en televisión. En: A. M. De Vicente Domínguez \& J. Sierra Sánchez. Aproximación periodística y educomunicativa al fenómeno de las redes sociales. (pp. 921-929). Madrid: McGraw-Hill.

Salas Abad, C. (2019). "La primera fake news de la historia". Historia y Comunicación Social, 24(2), 411-431.https://dx.doi.org/10.5209/hics.66268

Sánchez-Gey Valenzuela, N. (2019). El aumento de las noticias falseadas y sus consecuencias en el que hacer de los profesionales de la información en televisión. Ámbitos. Revista Internacional de Comunicación, 45, 159-181. http://dx.doi.org/10.12795/Ambitos.2019.i45.10

Silverio Moreno, P. (2018). El rigor informativo en la era de la posverdad: la amenaza de las fake news en las redes sociales. Comunicación y Hombre, 15,1-12. https://bit.ly/36EZxv2

Shu, K.; Sliva, A.; Wang, S.; Tang, J. \& Liu, H. (2017). Fake news detection on social media: a data mining perspective. ACM SIGKDD Explor. Newslett. 19(1), 22-36. https://bit.ly/3euatyg

Tandoc Jr, E. C.; Lim, Z. W. \& Ling, R. (2018). Defining "fake news" A typology of scholarly definitions. Digital Journalism, 6(2), 137-153. https://doi.org/10.1080/21670811.2017.1360143

Terradillos, A. (2020). Guardia Civil insta a identificar fake news susceptibles de crear "desafección a instituciones del Gobierno". Cadena Ser, 20 de abril. https://bit.ly/3cb80HI

The lancet (2020). Covid-19: fighting panic with information. The lancet, 395(10224), p. 537. https://doi.org/10.1016/S0140-6736(20)30379-2

S.E. (2020). La Moncloa estudia que los responsables policiales y del Ejército no participen en las ruedas de prensa. Diario ABC, 20 abril. https://bit.ly/2ZLEZj7

Vara-Miguel, A. (2018). Las noticias falsas o "fake news" preocupan al 69\% de internautas en España. https://bit.ly/2XBOXRq

Vara-Miguel, A. (2019). Ante una confianza decreciente, la mayoría de los usuarios españoles se previene de la desinformación. https://bit.ly/2XFOygJ

Vázquez-Herrero, J.; Vizoso, Á. \& López-García, X. (2019). Innovación tecnológica y comunicativa para combatir la desinformación: 135 experiencias para un cambio de rumbo. El profesional de la información, 28(3), e280301, 12. https://doi.org/10.3145/epi.2019.may.01

Vega, G. (2020). Facebook atribuye a una red de 'spam' con actividad global las cuentas falsas que daban 'like' a Sanidad. El País, 22 de abril. https://elpais.com/tecnologia/2020-04-22/facebookatribuye-a-una-red-de-spam-con-actividad-global-las-cuentas-falsas-que-daban-like-asanidad.html

Zuazo, N. (2018). Los dueños de Internet. Cómo nos dominan los gigantes de la tecnología y qué hacer para cambiarlo. Buenos Aires (Argentina): Penguin Random House Grupo. 


\section{AUTORES}

\section{Aránzazu Román-San-Miguel}

En la actualidad es ayudante de dirección del Máster en Periodismo Deportivo de la Universidad de Sevilla y miembro del Grupo de Investigación: Estrategias de Comunicación. Doctora en Periodismo, es Licenciada en Periodismo y Experta Universitaria en Comunicación Institucional y Marketing Político. Ha sido profesora en el Departamento de Periodismo II y co-coordinadora y profesora del Máster en Comunicación Institucional y Política en la universidad hispalense. Ha escrito varios libros, capítulos de libro y artículos en revistas sobre periodismo, especialización periodística, protocolo y comunicación institucional. Ha realizado estancias de investigación en la Universidad Complutense de Madrid, en la Universidad de Castilla La Mancha y en la Universidad Pontificia Salesiana de Roma. arantxa@us.es

Índice H: 2

Orcid ID: https://orcid.org/0000-0002-9131-2629

Google Scholar: https://scholar.google.com/citations?user=KQIS z0AAAAJ\&hl=es\&authuser=1

Research ID: https://publons.com/researcher/2279421/aranzazu-arsm-roman-san-miguel/

Scopus: https://www.scopus.com/authid/detail.uri?authorId=56041639800

ResearchGate: https://www.researchgate.net/profile/Aranzazu Roman San Miguel

Dialnet: https://dialnet.unirioja.es/servlet/autor?codigo=2598513

\section{Nuria Sánchez-Gey-Valenzuela}

Actualmente es periodista, doctora en Comunicación, licenciada en Periodismo. Ha trabajado durante más de quince años en medios de comunicación locales, autonómicos y nacionales, en prensa, radio y televisión, aunque se ha especializado en este último. También ha impartido clases en la Escuela de Reporteros de Andalucía y ha sido docente en el Aula de la Experiencia de la Universidad de Sevilla.

$\mathrm{Su}$ tesis doctoral es un análisis del sector audiovisual y la televisión pública, realizada desde el enfoque estructural de la Economía Política de la Información, que su campo de investigación. Asimismo, forma parte del equipo de investigación de Estructura de la Información dirigido por el catedrático Ramón Reig de la Universidad de Sevilla. nuriasanchezgey@gmail.com

Índice H: 1

Orcid ID: https://orcid.org/0000-0002-4891-9134

Google Scholar: https://scholar.google.com/citations?user=EclOYpwAAAAJ\&hl=es

Dialnet: https://dialnet.unirioja.es/servlet/autor?codigo $=2431260$

\section{Rodrigo Elías-Zambrano}

Profesor Ayudante Doctor en el Departamento de Comunicación Audiovisual y Publicidad de la Universidad de Sevilla. Es Doctor en Comunicación, Licenciado en Comunicación Audiovisual y Máster en Gestión de Empresas AV por la Universidad de Sevilla, Máster en Comunicación y Educación AV por la Universidad de Huelva y Experto en E-Learning. Ha sido profesor en el Departamento de Marketing y Comunicación de la Universidad de Cádiz y actualmente, colabora con la Universitat Oberta de Catalunya. Es, además, miembro del Grupo de investigación SEJ420 (IDECO - Comunicación Política, Ideología y Propaganda). A nivel profesional, está ligado al mundo de la realización AV publicitaria a nivel nacional e internacional, para a la RAI, la CNBC, Al Jazeera, TVP o NHK. rodrigoelias@us.es

Índice H: 5

Orcid ID: http://orcid.org/0000-0001-8256-582X

Google Scholar: https://scholar.google.es/citations?user=659XcUcAAAAJ\&hl=es

Research ID: https://publons.com/researcher/3426900/rodrigo-elias/

Scopus: $\underline{\text { https://www.scopus.com/authid/detail.uri?authorId=55579265900 }}$

ResearchGate: https://www.researchgate.net/profile/Rodrigo_Elias_Zambrano

Dialnet: https://dialnet.unirioja.es/servlet/autor?codigo $=3015357$

\footnotetext{
${ }^{\text {i }}$ Palabras pronunciadas en rueda de prensa y reproducidas por todos los medios de comunicación españoles
} 